\title{
MOLECULAR AND ATOMIC GAS IN THE LARGE MAGELLANIC CLOUD. II. THREE-DIMENSIONAL CORRELATION BETWEEN CO AND H I
}

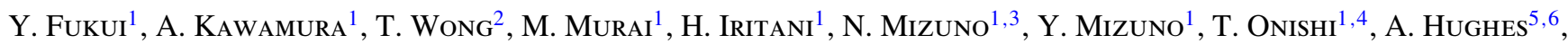 \\ J. Otт ${ }^{7,8}$, E. MulleR ${ }^{1}$, L. Staveley-Smith ${ }^{9}$, And S. Kim ${ }^{10}$ \\ ${ }^{1}$ Department of Astrophysics, Nagoya University, Furocho, Chikusaku, Nagoya 464-8602, Japan; fukui@a.phys.nagoya-u.ac.jp, kawamura@ a.phys.nagoya-u.ac.jp \\ 2 Astronomy Department, University of Illinois, 1002 W. Green Street, Urbana, IL 61801, USA \\ ${ }^{3}$ National Astronomical Observatory of Japan, 2-21-1 Osawa, Mitaka, Tokyo 181-8588, Japan \\ ${ }^{4}$ Department of Physical Science, Osaka Prefecture University, Gakuen 1-1, Sakai, Osaka 599-8531, Japan \\ ${ }^{5}$ Centre for Astrophysics and Supercomputing, Swinburne University of Technology, P.O. Box 218, Hawthorn, VIC 3122, Australia \\ ${ }^{6}$ CSIRO Australia Telescope National Facility, P.O. Box 76, Epping, NSW 1710, Australia \\ ${ }^{7}$ National Radio Astronomy Observatory, 520 Edgemont Road, Charlottesville, VA 22903, USA \\ ${ }^{8}$ California Institute of Technology, MC 10524, Pasadena, CA 91125, USA \\ ${ }^{9}$ School of Physics M013, University of Western Australia, Crawley, WA 6009, Australia \\ ${ }^{10}$ Department of Astronomy and Space Science, Sejong University, KwangJin-gu, KunJa-dong 98, Seoul 143-747, Korea \\ Received 2008 December 19; accepted 2009 September 3; published 2009 October 8
}

\begin{abstract}
We compare the $\mathrm{CO}(J=1-0)$ and $\mathrm{H}$ I emission in the Large Magellanic Cloud in three dimensions, i.e., including a velocity axis in addition to the two spatial axes, with the aim of elucidating the physical connection between giant molecular clouds (GMCs) and their surrounding $\mathrm{H}$ I gas. The CO $J=1-0$ data set is from the second NANTEN CO survey and the Hi data set is from the merged Australia Telescope Compact Array (ATCA) and Parkes Telescope surveys. The major findings of our analysis are as follows: (1) GMCs are associated with an envelope of $\mathrm{H}$ I emission, (2) in GMCs [average CO intensity] $\propto$ [average $\mathrm{H}_{\mathrm{I}}$ intensity] ${ }^{1.1 \pm 0.1}$, and (3) the $\mathrm{H}$ i intensity tends to increase with the star formation activity within GMCs, from Type I to Type III. An analysis of the H I envelopes associated with GMCs shows that their average line width is $14 \mathrm{~km} \mathrm{~s}^{-1}$ and the mean density in the envelope is $10 \mathrm{~cm}^{-3}$. We argue that the $\mathrm{H}$ I envelopes are gravitationally bound by GMCs. These findings are consistent with a continual increase in the mass of GMCs via H I accretion at an accretion rate of $0.05 M_{\odot} \mathrm{yr}^{-1}$ over a timescale of $10 \mathrm{Myr}$. The growth of GMCs is terminated via dissipative ionization and/or stellar-wind disruption in the final stage of GMC evolution.
\end{abstract}

Key words: galaxies: ISM - ISM: atoms - ISM: clouds - ISM: molecules - Magellanic Clouds - radio lines: ISM

Online-only material: color figures

\section{INTRODUCTION}

Giant molecular clouds (GMCs), the most massive aggregations of interstellar matter with $10^{5}-10^{6} M_{\odot}$, are the principal sites of star formation in galaxies. It is important to understand how GMCs are formed out of the less dense atomic interstellar gas in order to understand galactic evolution. The interstellar $\mathrm{H} \mathrm{I}$ gas has densities of less than several $10 \mathrm{~cm}^{-3}$, while molecular clouds have densities larger than $100 \mathrm{~cm}^{-3}$. It is reasonable to assume that $\mathrm{HI}$ is being converted into $\mathrm{H}_{2}$ either by thermal/ gravitational instabilities and/or shock compressions, although the detailed processes of this conversion are not yet well understood. Sato \& Fukui (1978) and Hasegawa et al. (1983) identified cold HI gas associated with GMCs in M17 and W3/4 and suggested that the cold $\mathrm{H}$ I gas may be converted into molecular gas for these GMCs. Subsequently, Wannier et al. (1983) showed that five molecular clouds are associated with warm Hi envelopes and suggested that such $\mathrm{H}$ I envelopes may be common around GMCs. Nonetheless, associations between GMCs and $\mathrm{H}_{\mathrm{I}}$ envelopes are difficult to identify systematically throughout the Galactic disk, since GMC samples are restricted to the solar vicinity due to the crowding effects (Andersson et al. 1991). As a consequence, the GMC-H I association has not been well established.

The Magellanic system-including the Large Magellanic Cloud (LMC), the Small Magellanic Cloud (SMC), and the Bridge-is an ideal laboratory to study star formation and molecular cloud evolution because of its proximity to the Milky Way (e.g., Fukui et al. 1999, 2008; Mizuno et al. 2001, 2006; Ott et al. 2008; Kawamura et al. 2009). We expect that the Magellanic system can also shed light on the physical connection between GMCs and their atomic surroundings. Indeed, the LMC may offer the best place for such a study because of its nearly face-on orientation and level of star formation activity. The LMC's molecular cloud population, which is best traced via the $\mathrm{CO}$ emission, provides a key to understand the galaxy's star formation. Molecular clouds are able to highlight the location of star formation due to their highly clumped distribution in both space and velocity. The LMC's atomic gas, by contrast, has lower densities and is only weakly coupled to sites of active star formation, but it is the most promising candidate for the mass reservoir of GMC formation (e.g., Blitz et al. 2007). We note, moreover, that cold H I gas has been detected in the LMC (e.g., Dickey et al. 1994; Kim et al. 1999), and that the correlation between CO and H I may provide crucial observational evidence about the molecular cloud formation process.

Wong et al. (2009) compared the Hi and CO emission throughout the LMC on a pixel-by-pixel basis using the second NANTEN CO and ATCA+Parkes H I data sets. These authors studied correlations between the integrated $\mathrm{CO}$ and $\mathrm{H}$ I intensities, where the latter was integrated over all velocities with $\mathrm{H} \mathrm{I}$ emission or over individual Gaussian components. They found that $\mathrm{CO}$ emission is associated with high intensity $\mathrm{H}$ I gas but that intense $\mathrm{HI}$ emission is not always associated with $\mathrm{CO}$. 
Table 1

Physical Properties of GMCs

\begin{tabular}{|c|c|c|c|c|c|c|}
\hline GMC Type & $\begin{array}{c}\text { Number of } \\
\text { GMCs }\end{array}$ & $\begin{array}{c}M_{\mathrm{CO}}{ }^{\mathrm{a}} \\
\left(\times 10^{5} M_{\odot}\right)\end{array}$ & $\begin{array}{c}R^{\mathrm{a}} \\
(\mathrm{pc})\end{array}$ & $\begin{array}{c}N(\mathrm{HI})^{\mathrm{b}} \\
\left(\times 10^{21} \mathrm{~cm}^{-2}\right)\end{array}$ & $\begin{array}{c}\Delta V_{\mathrm{LSR}}\left(\mathrm{HI}_{\mathrm{I}}\right)^{\mathrm{b}} \\
\left(\mathrm{km} \mathrm{s}^{-1}\right)\end{array}$ & $\begin{array}{c}\Delta V_{\mathrm{LSR}}(\mathrm{CO})^{\mathrm{a}} \\
\left(\mathrm{km} \mathrm{s}^{-1}\right)\end{array}$ \\
\hline Type I & 72 & $2(2)$ & 37 (16) & $\cdots$ & $\cdots$ & $5.0(2.5)$ \\
\hline Type II & 142 & $2(3)$ & 33 (19) & $\cdots$ & $\cdots$ & $4.8(2.2)$ \\
\hline Type III & 58 & $5(10)$ & $51(36)$ & $\cdots$ & $\cdots$ & $6.9(3.0)$ \\
\hline Type I (selected) ${ }^{\mathrm{c}}$ & 24 & $2(3)$ & 35 (17) & $2.4(0.9)$ & $13.9(4.0)$ & $4.5(2.1)$ \\
\hline Type II (selected) ${ }^{\mathrm{c}}$ & 67 & $2(3)$ & $41(22)$ & $2.6(1.2)$ & $14.6(4.1)$ & $4.4(1.6)$ \\
\hline Type III (selected) ${ }^{\mathrm{c}}$ & 32 & $4(3)$ & $55(23)$ & $3.3(1.5)$ & $16.1(3.3)$ & $5.5(1.5)$ \\
\hline
\end{tabular}

Notes. Average properties of the GMCs. The values in parentheses are the standard deviation.

${ }^{a}$ Fukui et al. (2008); Kawamura et al. (2009).

b Half-intensity full width derived by Gaussian fitting.

c Selected clouds having single-peaked H i profiles.

They also discovered a weak tendency for $\mathrm{CO}$ to be associated with H I components that have relatively low velocity dispersion. This suggests that energy dissipation of the H I gas may be required for the formation of molecular clouds. Following the global analysis by Wong et al. (2009), we focus here on the $\mathrm{H}$ I associated with individual GMCs in the LMC. In order to address this issue, we conduct a detailed comparison between the $\mathrm{CO}$ and $\mathrm{HI}$ emission in three dimensions, i.e., $(x, y, v)$, at a spatial resolution of $\sim 40 \mathrm{pc}$ and a velocity resolution of $1.7 \mathrm{~km} \mathrm{~s}^{-1}$. The present study is complementary to the work by Wong et al. (2009); in conjunction, the two studies provide a new insight into the CO-H I connection. In Section 2, we briefly review the basic observational properties of GMCs in the LMC. In Section 3, we describe our method of analyzing the CO-H I correlation and present our results. We discuss the physical interpretation of our results in Section 4, and provide a summary of our major conclusions in Section 5.

\section{GMCs IN THE LMC: THE SECOND NANTEN CO SURVEY}

The LMC is extended by more than $30 \mathrm{deg}^{2}$ across the sky and it has been a difficult task to make a systematic survey of the $\mathrm{CO}$ emission at angular resolutions sufficient to resolve individual GMCs. Fukui et al. (1999) made such a survey in the $2.6 \mathrm{~mm}$ CO line with the NANTEN $4 \mathrm{~m} \mathrm{~mm}$-wave telescope and published the first results in Fukui et al. (1999). Subsequently, these authors completed another survey of the LMC, improving the sensitivity by a factor of 2 . The second NANTEN CO survey has cataloged 272 GMCs (Fukui et al. 2008). The basic physical parameters of GMCs in the LMC are similar to those in the Milky Way and other nearby galaxies. Their masses range from $\sim 10^{5} M_{\odot}$ to $\sim 10^{6} M_{\odot}$; the mass spectrum is quite steep with a slope of $d N / d M \sim M^{-2}$. The $\mathrm{X}$ factor, the ratio of the $\mathrm{H}_{2}$ column density to $\mathrm{CO}$ intensity, is $\sim 7 \times 10^{20} \mathrm{~cm}^{-2}\left(\mathrm{~K} \mathrm{~km} \mathrm{~s}^{-1}\right)^{-1}$ (Fukui et al. 2008; Blitz et al. 2007). The complete sampling of the NANTEN survey has also allowed us to make a statistical study of GMCs with various young objects including $\mathrm{H}$ II regions and young stellar clusters. Kawamura et al. (2009) confirmed that there are three classes of GMCs that can be categorized according to their association with young star clusters as originally indicated in the analysis of the first NANTEN LMC survey (Fukui et al. 1999; Yamaguchi et al. 2001). Type I GMCs show no signs of active star formation in the sense that no $\mathrm{O}$ stars are being formed. Type II GMCs are associated with small $\mathrm{H}$ II region(s), indicating the formation of isolated $\mathrm{O}$ stars, but do not host any stellar clusters identified by Bica et al. (1996). Type III GMCs are actively forming stars as shown by their association with large $\mathrm{H}$ II regions and young stellar clusters. These classes are interpreted as an evolutionary sequence from Type I to III; the lifetime of a GMC is estimated to be a few $\times 10 \mathrm{Myr}$ in total (Kawamura et al. 2009). The stage after Type III is likely to be a very violent dissipation of the GMC due to the UV photons and stellar winds produced by the nascent clusters, as seen spectacularly in the region of 30 Dor (Yamaguchi et al. 2001). A comparison of the physical parameters of the GMCs shows that the size and mass of the clouds tend to increase from Type I/II to Type III. A summary of the average mass and size for the three GMC classes is presented in Table 1, as taken from Kawamura et al. (2009).

\section{CORRELATION BETWEEN CO AND H I}

\subsection{Three-dimensional Correlation}

Previous studies of star formation in galaxies have employed two-dimensional (2D) maps of $\mathrm{HI}$ intensity with large spatial averaging on scales between $\sim 100 \mathrm{pc}$ and $1 \mathrm{kpc}$ (e.g., Schmidt 1972; Kennicutt 1998). Here, we make a three-dimensional (3D) comparison between the $\mathrm{CO}$ and $\mathrm{HI}$ in the LMC where the 3D datacubes have a velocity axis in addition to two spatial axes projected on the sky. Preliminary results of the comparison have been published elsewhere (Fukui 2007). We use the 3D datacube of CO obtained with NANTEN (Fukui et al. 2008) and an H I datacube obtained with ATCA and Parkes (Kim et al. 2003). The CO emission traces GMCs and the Hi emission traces less dense atomic gas. Figure 1 shows an overlay of the velocity-integrated intensities of the $\mathrm{CO}$ and $\mathrm{HI}$ emission; from this, it is clear that GMCs in the LMC tend to be located toward $\mathrm{H}$ I filaments or local $\mathrm{H}$ I peaks, suggesting that $\mathrm{HI}$ is a prerequisite for GMC formation (Blitz et al. 2007). However, it is also clear that there are many $\mathrm{H}$ I peaks and filaments without $\mathrm{CO}$ emission (Wong et al. 2009). Figure 2 shows typical CO and $\mathrm{HI}$ line profiles in the LMC. The $\mathrm{CO}$ emission is highly localized in velocity: the $\mathrm{HI}$ emission ranges over $100 \mathrm{~km} \mathrm{~s}^{-1}$, while the $\mathrm{CO}$ emission has a typical line width of less than $10 \mathrm{~km} \mathrm{~s}^{-1}$. We note that the large velocity dispersion of $\mathrm{HI}$ may be dominated by physically unrelated velocity components along the line of sight, i.e., the H I gas associated with the GMC may only be the small fraction of $\mathrm{H}$ I with velocities close to that of the $\mathrm{CO}$ emission. Previous studies of the $\mathrm{CO}-\mathrm{H}$ I connection that use velocity-integrated 2D maps may therefore overestimate the intensity of the associated $\mathrm{HI}$ emission along each line of sight. By making use of the velocity dimension, the present $3 \mathrm{D}$ analysis may allow us to identify the $\mathrm{HI}$ gas that is physically connected to the GMCs. The NANTEN and 


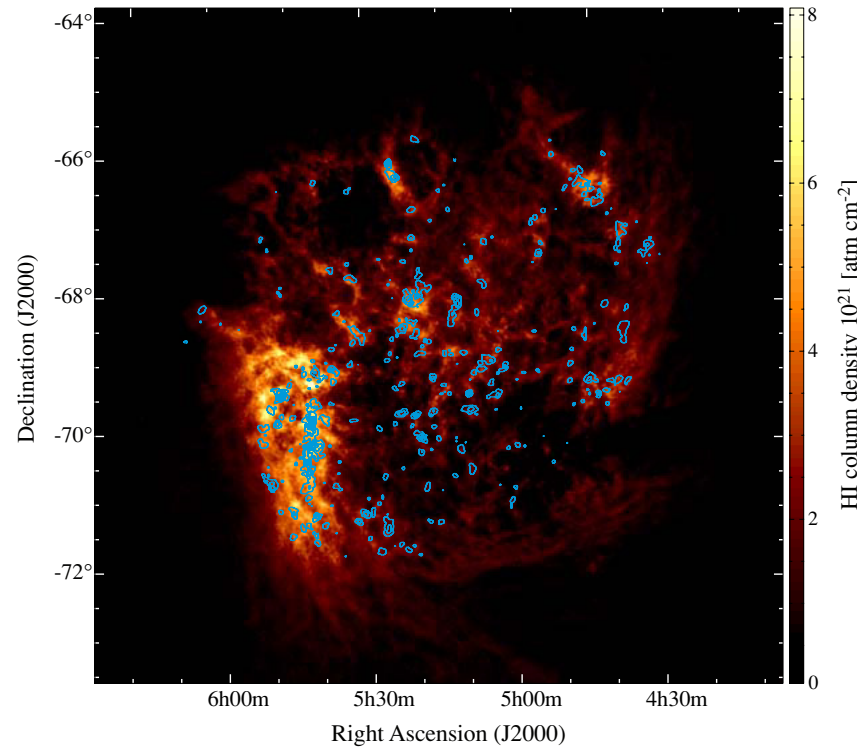

Figure 1. H I integrated intensity image (Kim et al. 2003) with contours of the CO integrated intensity (Fukui et al. 2008). The contour levels begin at $1.2 \mathrm{~K} \mathrm{~km} \mathrm{~s}^{-1}$ and have $3.6 \mathrm{~K} \mathrm{~km} \mathrm{~s}^{-1}$ intervals.

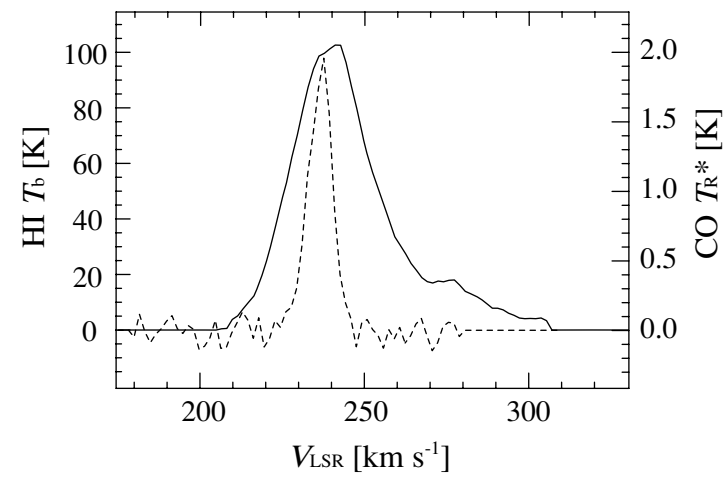

Figure 2. Example of the $\mathrm{H}_{\mathrm{I}}$ and CO line profiles at $\alpha(\mathrm{J} 2000)=5^{\mathrm{h}} 39^{\mathrm{m}} 38^{\mathrm{s}}$ and $\delta(\mathrm{J} 2000)=-69^{\circ} 44^{\prime} 46^{\prime \prime}$.

ATCA+Parkes datacubes have somewhat different spatial and velocity resolutions, so we have convolved both data sets to a spatial resolution of $40 \mathrm{pc} \times 40 \mathrm{pc}$, and a velocity resolution of $1.7 \mathrm{~km} \mathrm{~s}^{-1}$. The total number of 3D pixels is approximately $2 \times 10^{6}$ across the area surveyed by NANTEN. The $\mathrm{H}$ I and CO intensities are expressed in units of $T_{\mathrm{b}}(\mathrm{K})$ and $T_{\mathrm{R}}^{*}(\mathrm{~K})$; the $3 \sigma$ noise levels of the $\mathrm{HI}$ and $\mathrm{CO}$ datacubes are $7.2 \mathrm{~K}$ and $0.21 \mathrm{~K}$, respectively. Strictly speaking, the one-to-one correspondence between a velocity and a position is not guaranteed because there is a chance that physically unrelated H I gas may have the same velocity as $\mathrm{HI}$ gas related to the GMC along the same line of sight. Our results identify the H I associated with GMCs and suggest that such contamination along individual sightlines may not be a serious problem. We further note that $\mathrm{H}$ I absorption toward background radio continuum sources does not affect significantly the $\mathrm{HI}_{\mathrm{I}}$ intensity at the present spatial resolution, as verified toward 30 Dor, one of the brightest radio continuum sources in the LMC.

Figure 3 shows a histogram of the $\mathrm{HI}_{\mathrm{I}}$ intensity in the 3D datacube. Pixels with the significant $\mathrm{CO}$ emission $\left(T_{\mathrm{R}}^{*}>0.21 \mathrm{~K}\right)$ are shown in red. Throughout this paper, histograms always use the values of 3D pixels with no spatial integration unless otherwise stated. The histogram in Figure 3 shows that the fraction of CO-detected pixels increases monotonically with the

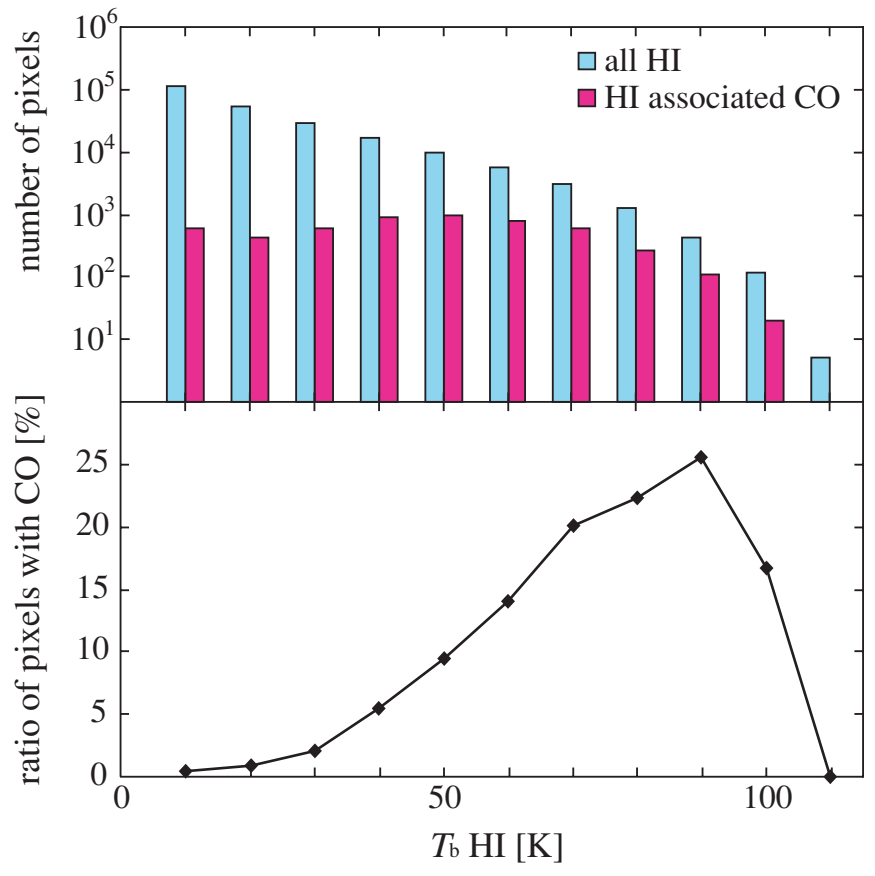

Figure 3. H I and CO datacubes used for our analysis have somewhat different spatial and velocity resolutions; we have convolved both data sets to a spatial resolution of $40 \mathrm{pc} \times 40 \mathrm{pc}$, and a velocity resolution of $\times 1.7 \mathrm{~km} \mathrm{~s}^{-1}$ across the whole LMC. The pixels used in our analysis occupy the same volumes for both the $\mathrm{HI}$ and $\mathrm{CO}$ data sets. The $3 \sigma$ detection limits for the $\mathrm{CO}$ and $\mathrm{HI}$ brightness are $0.21 \mathrm{~K}$ and $7.2 \mathrm{~K}$, respectively. (a) Histogram of the $\mathrm{HI}$ brightness temperature averaged within each $3 \mathrm{D}$ pixel is shown in blue; the $\mathrm{H}_{\mathrm{I}}$ pixels with significant $\mathrm{CO}$ emission (i.e., $>3 \sigma$ ) are marked in red. The width of the histogram bins is $10 \mathrm{~K}$. (b) Ratio of the number of pixels with significant $\mathrm{H}$ I emission to those with significant $\mathrm{CO}$ emission within each $10 \mathrm{~K}$ bin.

$\mathrm{H}_{\mathrm{I}}$ intensity, suggesting the $\mathrm{H} \mathrm{I}$ intensity is a necessary condition to form GMCs, consistent with the conclusion by Wong et al. (2009). About one-third of the pixels with $T_{\mathrm{b}}(\mathrm{HI})$ of $\sim 90 \mathrm{~K}$ exhibit $\mathrm{CO}$ emission, but it seems that there is no sharp threshold value of $\mathrm{H}$ i intensity that is required for GMC formation.

Figure 4 shows a histogram of the $\mathrm{H}$ i intensity for the three GMC types. Each pixel detected in $\mathrm{CO}$ belongs to one of the GMCs cataloged in Fukui et al. (2008). Figure 4 clearly shows that the Hi intensity tends to increase from Type I to Type III, although the dispersion is considerable. The average H I intensity for Types I, II, and III GMCs across the LMC is $34 \pm 16 \mathrm{~K}(1 \sigma), 47 \pm 17 \mathrm{~K}$, and $56 \pm 19 \mathrm{~K}$, i.e., the average $\mathrm{H} \mathrm{I}$ intensity increases with the level of star formation activity within the GMC. In order to test for variation within the galaxy, we tentatively divide the galaxy into three regions, i.e., Bar, North, and Arc, as shown in Figure 4 (right). Histograms for each region, shown in the lower three panels of Figure 4, reveal the same trend, suggesting that the present trend is common over the whole LMC. The total number of pixels in each region is 429,510, 666,060, and 405,093. Type I, Type II, and Type III GMCs include 330, 1065, and 639 pixels in the Bar region; 346 , 878 , and 1158 pixels in the North region; and 389, 650, and 1231 pixels in the Arc region.

Figure 5 shows the velocity channel maps of the $\mathrm{H}_{\mathrm{I}}$ distribution associated with Type I, Type II, and Type III GMCs. These channel maps clearly show that the $\mathrm{H}$ i is associated with the $\mathrm{CO}$. The $\mathrm{CO}$ distribution has small structures of $\sim 100 \mathrm{pc}$ or less and the $\mathrm{HI}$ appears to be associated with the GMC on larger scales of $\sim 100$ to $400 \mathrm{pc}$. The $\mathrm{HI}$ emission is not always symmetric with respect to a GMC, even though H I typically 

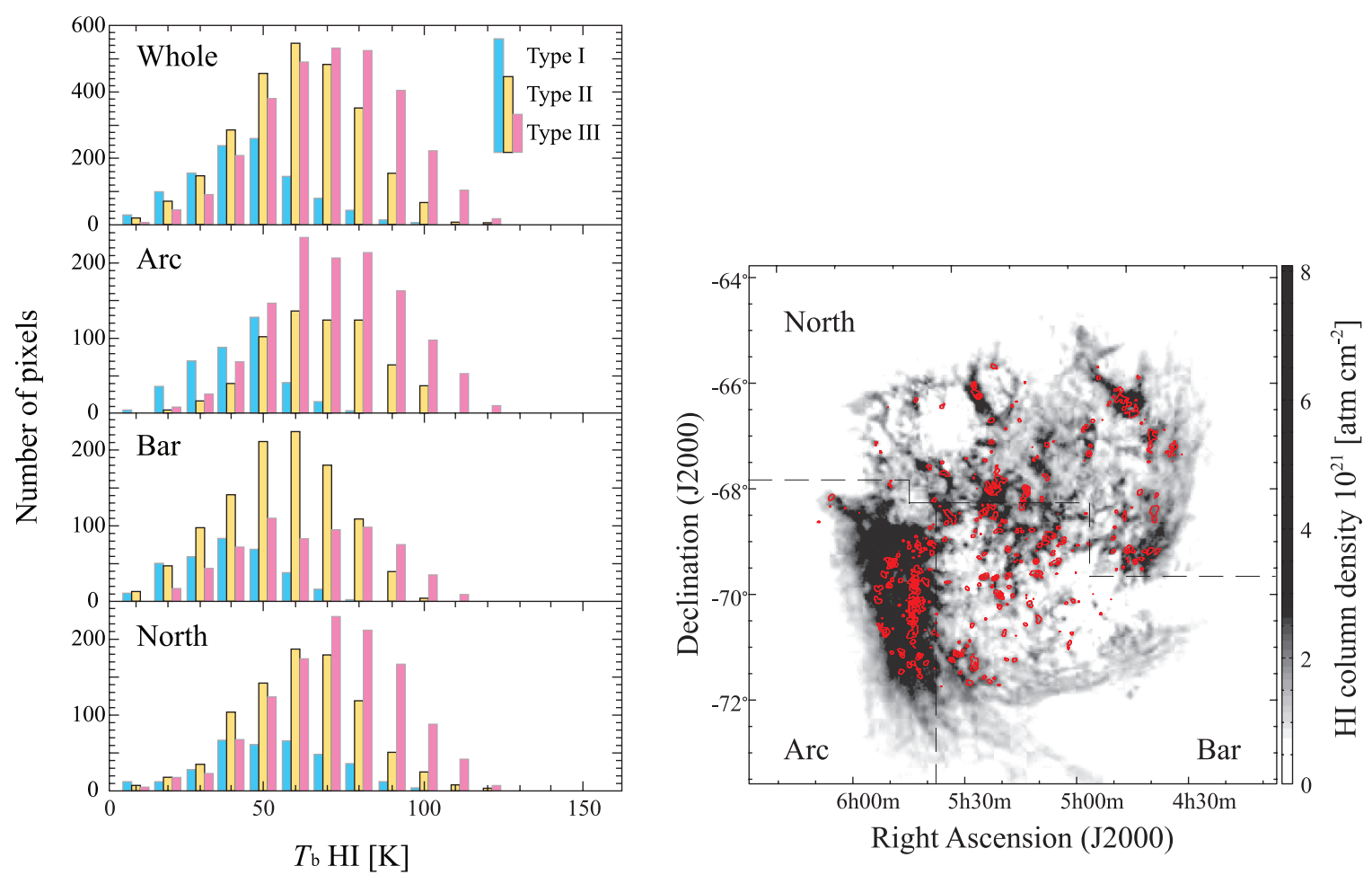

Figure 4. Histograms of the pixel-averaged $\mathrm{H}$ I brightness temperature where significant CO emission is detected for Type I (blue), Type II (yellow), and Type III (red) GMCs. Histograms are shown for the whole LMC, and for three different regions—Bar, North, and Arc — which are indicated in the right panel.

(A color version of this figure is available in the online journal.)

envelopes each GMC. The associated $\mathrm{HI}$ is often elongated along the GMCs and the region of intense H I emission is usually $<100 \mathrm{pc}$ wide. The $\mathrm{CO}$ emission typically extends over a velocity range of $\sim 5 \mathrm{~km} \mathrm{~s}^{-1}$; beyond a few times this velocity range, the associated $\mathrm{HI}$ emission generally becomes much weaker or disappears.

\subsection{Physical Properties of the H I Envelope}

In general, it is a complicated task to derive reliable physical properties of the HI gas associated with a GMC because the $\mathrm{H}$ I profiles are a blend of several different components along the line of sight, making it difficult to select the $\mathrm{HI}$ gas that is physically connected to a GMC. Another obstacle is that the $\mathrm{H} \mathrm{I}$ emission is spatially more extended than the $\mathrm{CO}$ emission and has a less clear boundary than the CO.

For our analysis, we first selected GMCs with simple singlepeaked H I profiles from the Fukui et al. (2008) catalog. The resulting sample consists of $123 \mathrm{GMCs}$ in total. Their catalog numbers and basic physical properties, taken from Fukui et al. (2008), are listed in Table 2. For these GMCs, we tested whether there was a bias in their location with respect to the kinematic center of the galaxy, in their $\mathrm{CO}$ line width or in their molecular mass. The histograms in Figure 6 indicate that there is no particular trend for these properties of the selected GMCs compared to GMCs in the complete catalog, suggesting that there is no appreciable selection bias. We applied a Kolmogorov-Smirnov test to the three histograms and calculated maximum deviations of $0.031,0.061$, and 0.117 , respectively, for the three parameters. These values are less than the critical deviation, 0.129 , for a conventional significance level of 0.05 , confirming that there is no selection bias.

Next, we made Gaussian fits to the $\mathrm{HI}$ and $\mathrm{CO}$ profiles toward the $\mathrm{CO}$ peak of each GMC. This procedure yields a peak intensity, peak velocity, and half-power line width for each line profile (a summary is given for each GMC type in Table 1). Figure 7 shows the relation between the $\mathrm{CO}$ line width and the difference between the $\mathrm{CO}$ and $\mathrm{H}$ i peak velocities. We find the $\mathrm{HI}$ and $\mathrm{CO}$ peak velocities to be in good agreement, showing only a small scatter of less than a few $\mathrm{km} \mathrm{s}^{-1}$. Figure 8 shows two histograms of the $\mathrm{HI}$ and $\mathrm{CO}$ line widths. We see that the $\mathrm{HI}$ line width is typically $14 \mathrm{~km} \mathrm{~s}^{-1}$, roughly three times larger than that of CO. Figure 9 shows a correlation between $\mathrm{HI}$ and $\mathrm{CO}$ line widths. The two quantities show a positive correlation with a correlation coefficient of 0.39 . The correlation coefficient is determined using the Spearman rank method throughout this paper. The kinematic properties of $\mathrm{HI}$ and $\mathrm{CO}$, as illustrated in Figures 7 and 9, lend further support to a physical association between the $\mathrm{HI}$ and $\mathrm{CO}$.

In order to estimate the size of the $\mathrm{H}$ I envelope surrounding each GMC, we construct an $\mathrm{H}$ I integrated intensity map of each GMC. First, we find the local peak in the $\mathrm{H}$ I intensity cube surrounding the $\mathrm{CO}$ emission, and then integrate the $\mathrm{H}$ I intensity over the velocity channels corresponding to the FWHM of the $\mathrm{H}$ I line profile at this peak position. Next we estimate the area, $S$, where the H I integrated intensity is greater than $80 \%$ of the value at the local H i peak. We then calculate the radius of the $\mathrm{HI}$ envelope, $R(\mathrm{HI})$, from its projected area, $S=\pi R(\mathrm{HI})^{2}$. The $\mathrm{HI}_{\mathrm{I}}$ integrated intensity is calculated for all the pixels with detectable $\mathrm{CO}$ emission; the spatial distribution of the $\mathrm{H}$ I emission generally shows a peak and a reasonably defined boundary. The $80 \%$ level was chosen after a few trials using different levels; it is the maximum value for which a reasonable H I size is obtained for 116 of the 123 envelopes. While $80 \%$ seems to be rather high for such a definition of a cloud envelope, the $\mathrm{H}$ I size can be unrealistically large compared to the $\mathrm{CO}$ cloud size along a filamentary $\mathrm{H}$ I distribution if we use a lower 


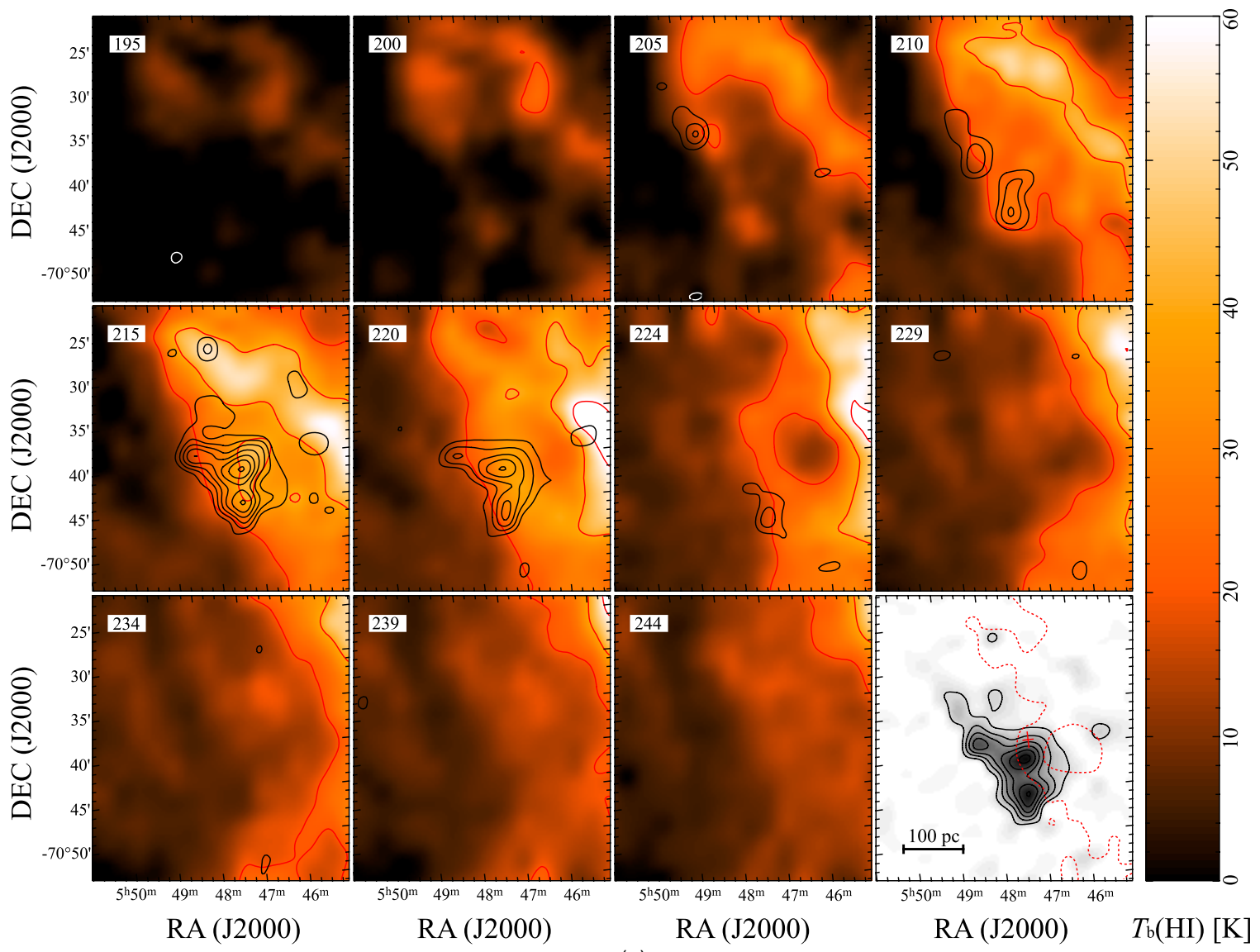

(a)

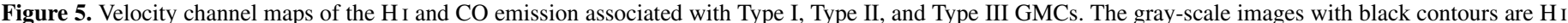

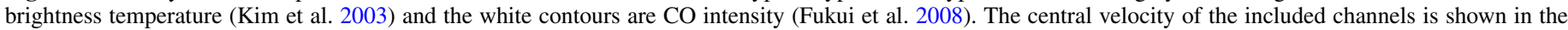

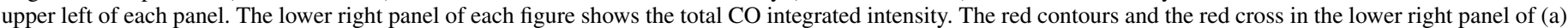

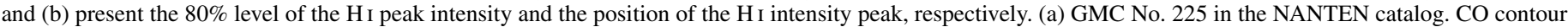

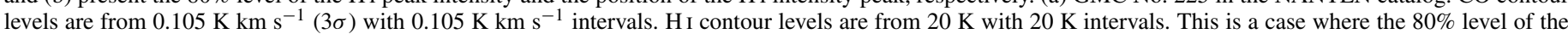

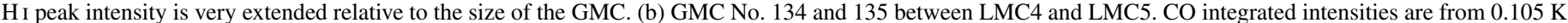

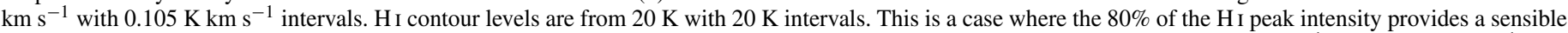

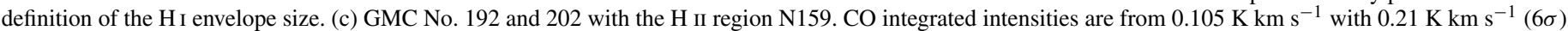

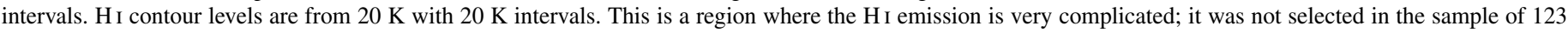
clouds that we use for our analysis.

level such as 60\%; an example is shown in Figure 5(b). The $\mathrm{H}_{\mathrm{I}}$ radius is then corrected for beam dilution by adopting Gaussian deconvolution with an H I FWHM of 2.6 arcmin, i.e., the same procedure that is applied to the radius of the GMC determined from the $\mathrm{CO}$ emission, $R(\mathrm{CO})$ (Kawamura et al. 2009). $R(\mathrm{CO})$, the $\mathrm{CO}$ peak position, $R(\mathrm{HI})$, the $\mathrm{H}_{\mathrm{I}}$ peak position, and the deviation between the peaks in parsecs, $\sqrt{\left(\Delta \alpha^{2}+\Delta \delta^{2}\right)}$, are listed in Table 2. Seven clouds, for which $R(\mathrm{HI})$ comprises only a few pixels, are denoted by asterisks. The physical extent of the H I envelopes can be as large as a few $100 \mathrm{pc}$. As long as we use the local H i peak of individual GMCs as our reference point, it seems difficult to contrive an alternative uniform definition of the envelope size that is difficult using the present $\mathrm{H}$ I data set.

In Figure 10, we show a histogram of the spatial deviation of the $\mathrm{HI}$ and $\mathrm{CO}$ peaks. This shows that nearly $80 \%$ of the $\mathrm{HI}$ envelopes peak within $120 \mathrm{pc}$ of the local $\mathrm{CO}$ peak, and that nearly $60 \%$ of the $\mathrm{HI}$ envelopes peak within $80 \mathrm{pc}$ of the $\mathrm{CO}$ peak. These separations may seem large compared to $R(\mathrm{HI})$, but we argue that they are reasonable if the $\mathrm{H} \mathrm{I}$ is enveloping $\mathrm{CO}$ at scales over $\sim 300 \mathrm{pc}$. It should be noted that the $\mathrm{H}$ i envelopes are not concentric with the CO emission, but are rather "enveloping" with some offsets in peak positions as illustrated in Figure 5. We thus expect to find some difference in general between the peak positions of the $\mathrm{CO}$ and $\mathrm{HI}_{\mathrm{I}}$ emission (as seen in Figure 10), but the fact that the majority of $\mathrm{H}$ I peaks are located within $120 \mathrm{pc}$ of the $\mathrm{CO}$ peaks is clearly suggestive of a physical association between the GMCs and their surrounding atomic gas. In Figure 11, we show a correlation between $R(\mathrm{HI})$ and $R(\mathrm{CO})$ for $62 \mathrm{GMCs}$ whose radius is greater than $30 \mathrm{pc}$ and find that they are positively correlated with a correlation coefficient of 0.45 . Despite the relatively flatter distribution of the $\mathrm{H}$, the size of the $\mathrm{H}$ I envelope does seem to correlate with the size of the GMC.

To summarize our analysis in this section, we find for the 123 GMCs with single-peaked H I profiles that (1) the peak velocities of the $\mathrm{CO}$ and $\mathrm{H}$ I are in good agreement (Figure 7); (2) the CO and $\mathrm{H}_{\mathrm{I}}$ line widths show a positive correlation (Figure 9); (3) the $\mathrm{H}$ I envelopes, defined using the $80 \%$ level of the local $\mathrm{H}$ I integrated intensity peak, are mostly $(\sim 80 \%)$ centered within $120 \mathrm{pc}$ of the peak CO position (Figure 10); and (4) the radius of the H I envelope is positively correlated with the size of the GMC for GMCs with radii greater than 30 pc (Figure 11). These four results lend further support to the idea that $\mathrm{H}$ I envelopes are physically associated with GMCs, reinforcing the impression 


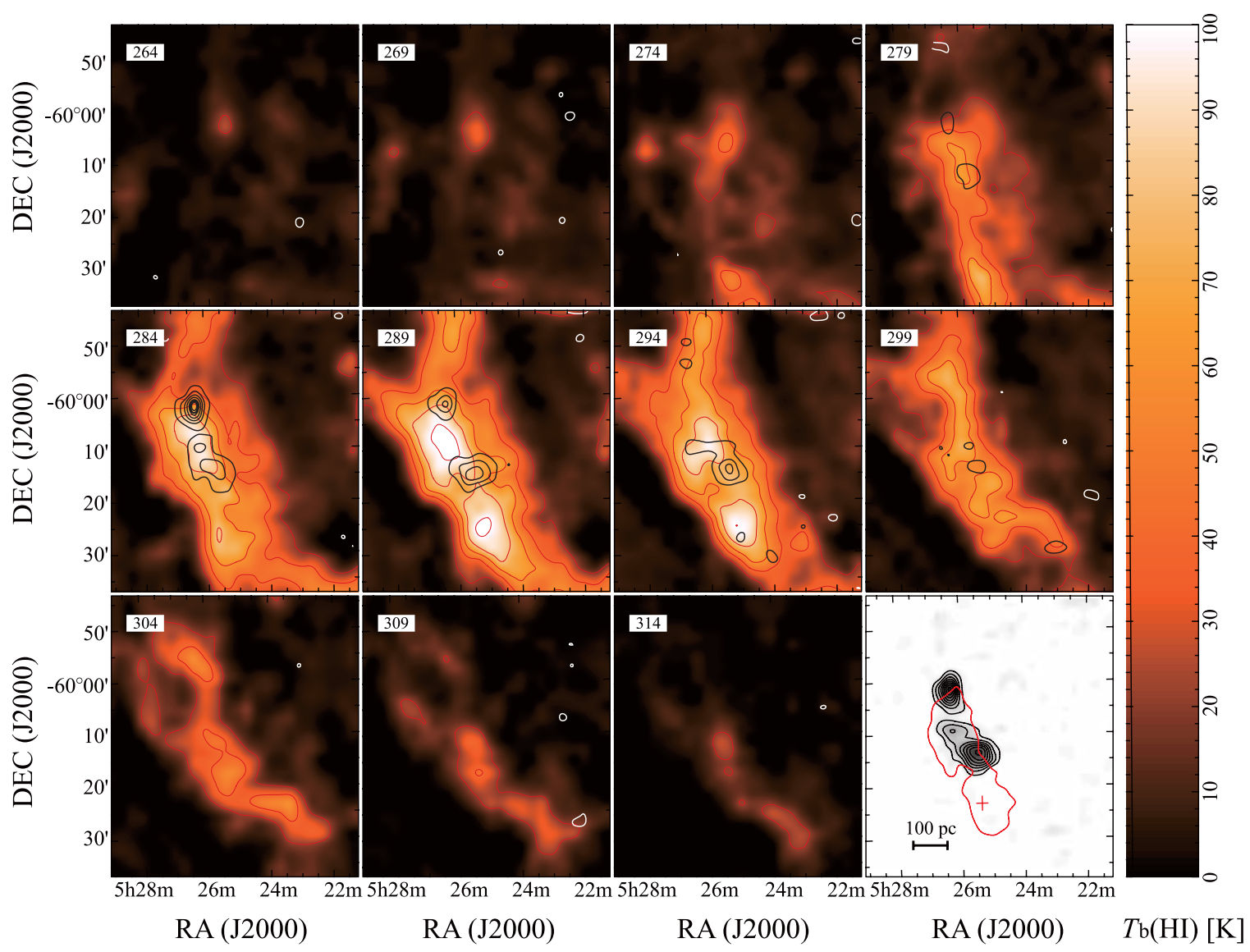

(b)

Figure 5. (Continued)

conveyed by a global comparison between the $\mathrm{H}$ i $\mathrm{CO}$ emission in the LMC (Figure 3) and the morphological similarity between the $\mathrm{CO}$ and $\mathrm{H} \mathrm{I}$ in individual velocity channels (Figure 5).

Next, we made an estimate of the Hi column density for the $123 \mathrm{GMCs}$ by using the relation $\left(N(\mathrm{HI})\left[\mathrm{cm}^{-2}\right]=\right.$ $\left.1.8 \times 10^{18} \int T_{\mathrm{b}} d v\left[\mathrm{~K} \mathrm{~km} \mathrm{~s}^{-1}\right]\right)$. The average values for the three GMC types are listed in Table 1 . We find that the peak $\mathrm{HI}$ column density is mostly in the range of $(2-5) \times 10^{21} \mathrm{~cm}^{-2}$. We estimate the typical density in the $\mathrm{H}$ I envelopes to be $\sim 10 \mathrm{~cm}^{-1}$ by dividing the peak H I column density $(2-5) \times 10^{21} \mathrm{~cm}^{-2}$ by the typical size of the associated H I 50-100 pc (see Figure 11). The mass of the $\mathrm{H}$ I envelopes is large, typically $\sim 5 \times 10^{4} \mathrm{M}_{\odot}$. The H I envelopes are likely gravitationally bound by GMCs because one-half of the $\mathrm{H}$ I line width, $7 \mathrm{~km} \mathrm{~s}^{-1}$, is nearly equal to $\sqrt{G M / R} \sim 6 \mathrm{~km} \mathrm{~s}^{-1}$ for $M=2 \times 10^{5} M_{\odot}$ and $R=40 \mathrm{pc}$, the average values of Type II GMCs.

In Figure 12, we plot the relationship between the average $\mathrm{CO}$ and Hi luminosity of the 123 GMCs. For each GMC, we selected pixels where $\mathrm{CO}$ emission is significantly detected: only these pixels are used to calculate the Hi luminosity of each cloud. In order to derive the average $\mathrm{CO}$ luminosity of a GMC, we estimated $I(\mathrm{CO})\left(\mathrm{K} \mathrm{km} \mathrm{s}^{-1}\right)$ by summing up the $\mathrm{CO}$ luminosity over all the pixels of a GMC and divide it by the area of the GMC. $I(\mathrm{HI})\left(\mathrm{K} \mathrm{km} \mathrm{s}^{-1}\right)$ is calculated in a similar manner, integrating the $\mathrm{H}$ i intensity over the FWHM velocity range at the CO peak of the GMC. The regression shown in Figure 12 is well fitted by a power law with an index of $\sim 1.1$, indicating a nearly linear correlation between $I(\mathrm{CO})$ and $I(\mathrm{HI})$ in a GMC.

\section{DISCUSSION}

\subsection{GMCs with H I Envelopes}

The present analysis has successfully identified the $\mathrm{HI}$ envelopes associated with GMCs on the basis of a 3D analysis of GMCs in the LMC. The H I intensity in the envelope depends on the star-forming activity within the GMC in the sense that the integrated $\mathrm{H}$ I intensity in the envelope increases from Type I to Type III (Figure 4, Section 3.1). In other words, massive GMCs have massive $\mathrm{H}$ i envelopes and less massive GMCs have less massive $\mathrm{H}$ I envelopes.

The $\mathrm{HI}_{\mathrm{I}}$ intensity is a product of the spin temperature and the optical depth of the H I $21 \mathrm{~cm}$ transition, provided that the line is optically thin. This is likely to be the case as the $\mathrm{H}$ I profiles show few hints of saturation like a flat top. The observed maximum $\mathrm{H}_{\mathrm{I}}$ brightness temperature is around $100 \mathrm{~K}$ and this suggests that the $\mathrm{HI}_{\mathrm{I}}$ spin temperature is significantly higher than $100 \mathrm{~K}$. Therefore, we infer that the Hi intensity should represent optical depth and, accordingly, H I column density, if the spin temperature is roughly uniform across the LMC. The Hi spin temperature in the LMC may be higher than in the Galaxy due to a more intense UV field and the lower dust extinction (Israel et al. 1996; Imara \& Blitz 2007; Dobashi et al. 2008). For the sake of discussion, we shall tentatively assume that the spin temperature lies between 150 and $600 \mathrm{~K}$ and is fairly uniform in the $\mathrm{HI}$ envelope. We note that the $\mathrm{HI}$ mass is accurately determined as long as the H I emission is optically thin. The H I mass does not depend on $T$ 's under the optically thin assumption, because the level populations of the 


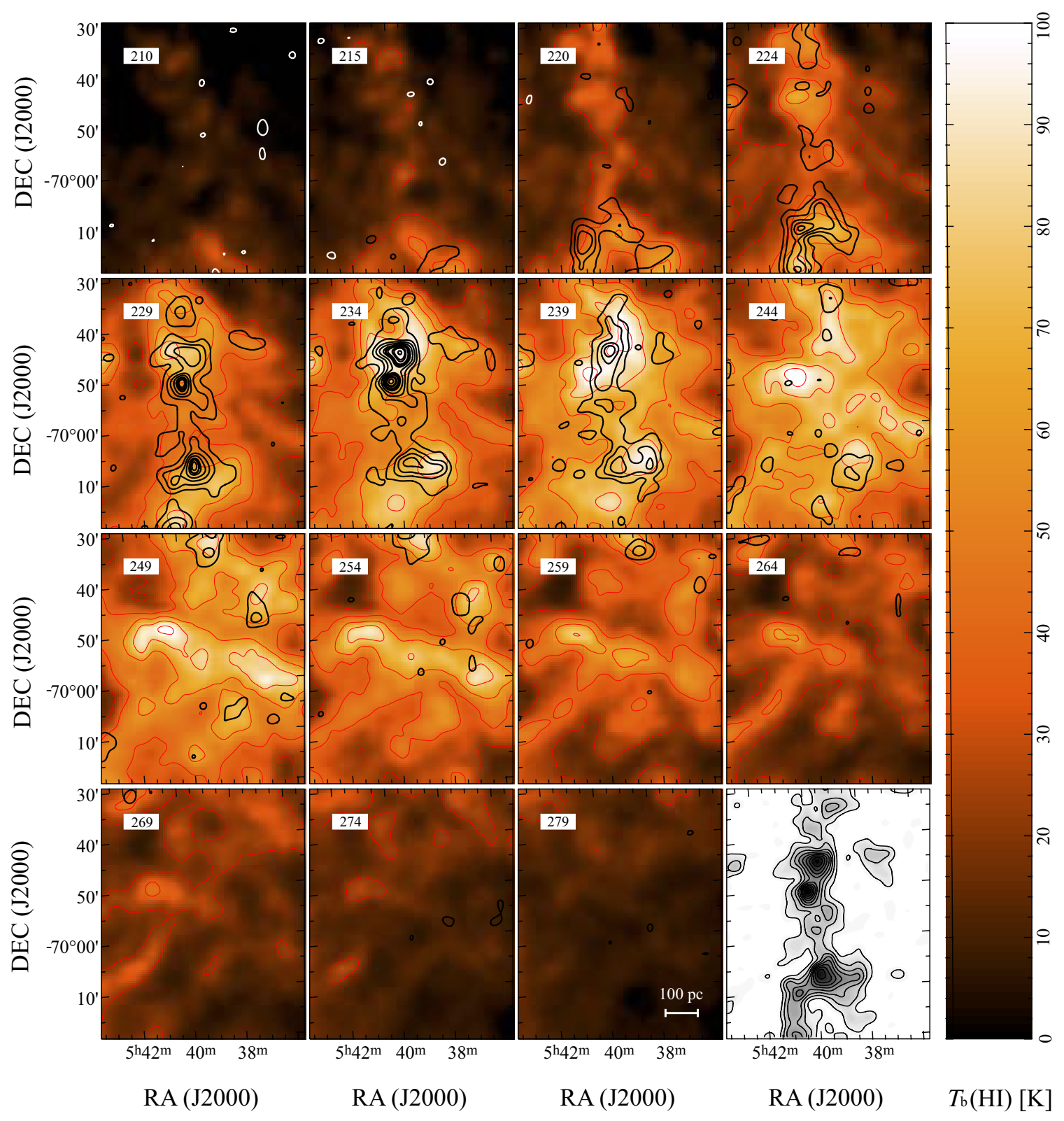

(c)

Figure 5. (Continued)

spin doublet having only $\sim 10^{-5} \mathrm{eV}$ is well thermalized in any realistic density range due to the slow magnetic dipole decay in $\sim 10^{7} \mathrm{yr}$.

Fukui et al. (1999) suggest that the three classes of GMC indicate an evolutionary sequence from Type I to Type III in a few 10 Myr (instead of "Type," these authors used "Class" with the same meaning). Kawamura et al. (2009) present a more detailed analysis of the association between GMCs and young stellar clusters, confirming Fukui et al.'s evolutionary scheme. These studies indicate that only the youngest star clusters with an age less than $\sim 10$ Myr are clearly associated with GMCs, and that older clusters with an age greater than $10 \mathrm{Myr}$ are not associated with GMCs. Assuming a steady state scenario, this implies that the natal gas of clusters is quickly disrupted within 10 Myr. Considering the complete sampling of both clusters and GMCs in the LMC, this strongly suggests that the population of Type III GMCs must be replenished on timescales of $10 \mathrm{Myr}$.
Since the typical timescale of GMC formation is at least $10 \mathrm{Myr}$, as estimated by the crossing timescale-i.e., the cloud size divided by its velocity dispersion, $100 \mathrm{pc} / 10 \mathrm{~km} \mathrm{~s}^{-1}=10 \mathrm{Myr}$, a measure of the minimum timescale for GMC formation-we expect to have a similar population of Type III GMCs and Type III precursors. A straightforward interpretation is that Type I and Type II GMCs are these precursors (see for details Kawamura et al. 2009). An alternative possibility is a more ad hoc situation in which Type III GMCs are formed suddenly in a few Myr by an external disturbance, such as a dynamical interaction. Such a strongly time-dependent scenario seems unlikely, however, since the three GMC types are fairly uniformly distributed over the LMC (Kawamura et al. 2009). Figure 4 also shows that the three classes of GMCs are distributed across the galaxy.

We have also seen that Type III GMC tend to be more massive than Type I and Type II GMCs (Table 2; Kawamura et al. 2009). A natural interpretation within the evolutionary scenario is that 
Table 2

List of Selected 123 GMCs

\begin{tabular}{|c|c|c|c|c|c|c|c|c|c|c|c|}
\hline \multirow[t]{2}{*}{ Number $^{\mathrm{a}}$} & \multirow[t]{2}{*}{ Name $^{\mathrm{a}}$} & \multirow[t]{2}{*}{ Type $^{b}$} & \multicolumn{2}{|c|}{ Peak Position $(\mathrm{CO})^{\mathrm{c}}$} & \multirow{2}{*}{$\begin{array}{c}R(\mathrm{CO})^{\mathrm{a}} \\
(\mathrm{pc})\end{array}$} & \multicolumn{2}{|c|}{ Peak Position $(\mathrm{HI})^{\mathrm{c}}$} & \multirow{2}{*}{$\begin{array}{c}R(\mathrm{H} \mathrm{I})^{\mathrm{d}} \\
(\mathrm{pc})\end{array}$} & \multirow{2}{*}{$\begin{array}{c}N(\mathrm{H} \mathrm{I})^{\mathrm{e}} \\
10^{21}\left(\mathrm{~cm}^{-2}\right)\end{array}$} & \multirow{2}{*}{$\begin{array}{c}\sqrt{\Delta \alpha^{2}+\Delta \delta^{2}} \mathrm{f} \\
(\mathrm{pc})\end{array}$} & Comment $^{g}$ \\
\hline & & & $\alpha(B 1950)$ & $\delta(B 1950)$ & & $\alpha(B 1950)$ & $\delta(B 1950)$ & & & & \\
\hline 1 & LMC N J0447-6910 & I & $4^{\mathrm{h}} 47^{\mathrm{m}} \cdot 7$ & $-69^{\circ} 14^{\prime}$ & 44 & $4^{\mathrm{h}} 47^{\mathrm{m}} \cdot 7$ & $-69^{\circ} 14^{\prime}$ & 34 & 2.6 & 0 & \\
\hline 4 & LMC N J0449-6910 & III & $4^{\mathrm{h}} 49^{\mathrm{m}} \cdot 1$ & $-69^{\circ} 16^{\prime}$ & 72 & $4^{\mathrm{h}} 49^{\mathrm{m}} \cdot 5$ & $-69^{\circ} 14^{\prime}$ & 74 & 2.7 & 91 & \\
\hline 5 & LMC N J0449-6826 & II & $4^{\mathrm{h}} 49^{\mathrm{m}} \cdot 5$ & $-68^{\circ} 28^{\prime}$ & 100 & $4^{\mathrm{h}} 50^{\mathrm{m}} \cdot 1$ & $-68^{\circ} 32^{\prime}$ & 77 & 1.7 & 152 & \\
\hline 9 & LMC N J0450-6930 & II & $4^{\mathrm{h}} 50^{\mathrm{m}} \cdot 5$ & $-69^{\circ} 36^{\prime}$ & 33 & $4^{\mathrm{h}} 50^{\mathrm{m}} \cdot 2$ & $-69^{\circ} 34^{\prime}$ & 55 & 2.1 & 83 & \\
\hline 11 & LMC N J0451-6858 & I & $4^{\mathrm{h}} 51^{\mathrm{m}} \cdot 3$ & $-69^{\circ} 4^{\prime}$ & 29 & $4^{\mathrm{h}} 51^{\mathrm{m}} \cdot 3$ & $-69^{\circ} 4^{\prime}$ & 29 & 2.7 & 0 & \\
\hline 12 & LMC N J0451-6704 & III & $4^{\mathrm{h}} 51^{\mathrm{m}} \cdot 9$ & $-67^{\circ} 8^{\prime}$ & 108 & $4^{\mathrm{h}} 52^{\mathrm{m}} \cdot 2$ & $-67^{\circ} 8^{\prime}$ & 62 & 3.2 & 70 & \\
\hline 17 & LMC N J0453-6909 & III & $4^{\mathrm{h}} 54^{\mathrm{m}} \cdot 1$ & $-69^{\circ} 14^{\prime}$ & 85 & $4^{\mathrm{h}} 53^{\mathrm{m}} \cdot 3$ & $-69^{\circ} 12^{\prime}$ & 59 & 2.1 & 159 & \\
\hline 22 & LMC N J0455-6830 & II & $4^{\mathrm{h}} 55^{\mathrm{m}} \cdot 9$ & $-68^{\circ} 36^{\prime}$ & 47 & $4^{\mathrm{h}} 55^{\mathrm{m}} \cdot 9$ & $-68^{\circ} 36^{\prime}$ & 18 & 2.2 & 0 & \\
\hline 23 & LMC N J0455-6634 & III & $4^{\mathrm{h}} 56^{\mathrm{m}} \cdot 4$ & $-66^{\circ} 42^{\prime}$ & 64 & $4^{\mathrm{h}} 56^{\mathrm{m}} \cdot 4$ & $-66^{\circ} 40^{\prime}$ & $*$ & 1.9 & 28 & $30,32,33,236$ \\
\hline 24 & LMC N J0455-6930 & III & $4^{\mathrm{h}} 56^{\mathrm{m}} \cdot 3$ & $-69^{\circ} 36^{\prime}$ & 29 & $4^{\mathrm{h}} 56^{\mathrm{m}} \cdot 3$ & $-69^{\circ} 36^{\prime}$ & 18 & 0.8 & 0 & \\
\hline 26 & LMC N J0457-6844 & III & $4^{\mathrm{h}} 57^{\mathrm{m}} \cdot 5$ & $-68^{\circ} 48^{\prime}$ & 29 & $4^{\mathrm{h}} 57^{\mathrm{m}} \cdot 5$ & $-68^{\circ} 48^{\prime}$ & 24 & 1.5 & 0 & \\
\hline 27 & LMC N J0457-6826 & III & $4^{\mathrm{h}} 57^{\mathrm{m}} \cdot 4$ & $-68^{\circ} 30^{\prime}$ & 40 & $4^{\mathrm{h}} 57^{\mathrm{m}} \cdot 1$ & $-68^{\circ} 32^{\prime}$ & 18 & 1.1 & 91 & \\
\hline 35 & LMC N J0459-6614 & II & $4^{\mathrm{h}} 58^{\mathrm{m}} \cdot 8$ & $-66^{\circ} 18^{\prime}$ & 79 & $4^{\mathrm{h}} 58^{\mathrm{m}} \cdot 4$ & $-66^{\circ} 24^{\prime}$ & 85 & 2.7 & 130 & $30,32,33,236$ \\
\hline 36 & LMC N J0500-6622 & II & $5^{\mathrm{h}} 0^{\mathrm{m}} \cdot 7$ & $-66^{\circ} 26^{\prime}$ & 52 & $5^{\mathrm{h}} 0^{\mathrm{m}} \cdot 7$ & $-66^{\circ} 26^{\prime}$ & 37 & 1.5 & 0 & \\
\hline 38 & LMC N J0502-6903 & II & $5^{\mathrm{h}} 2^{\mathrm{m}} \cdot 4$ & $-69^{\circ} 6^{\prime}$ & 37 & $5^{\mathrm{h}} 2^{\mathrm{m}} \cdot 4$ & $-69^{\circ} 6^{\prime}$ & 41 & 2.1 & 0 & \\
\hline 39 & LMC N J0503-6553 & II & $5^{\mathrm{h}} 3^{\mathrm{m}}$ & $-65^{\circ} 58^{\prime}$ & 40 & $5^{\mathrm{h}} 3^{\mathrm{m}}$ & $-65^{\circ} 58^{\prime}$ & 62 & 2.7 & 0 & \\
\hline 40 & LMC N J0503-6540 & II & $5^{\mathrm{h}} 3^{\mathrm{m}} \cdot 1$ & $-65^{\circ} 44^{\prime}$ & 37 & $5^{\mathrm{h}} 3^{\mathrm{m}} \cdot 4$ & $-65^{\circ} 46^{\prime}$ & 24 & 0.6 & 75 & \\
\hline 41 & LMC N J0503-6828 & II & $5^{\mathrm{h}} 3^{\mathrm{m}} \cdot 6$ & $-68^{\circ} 32^{\prime}$ & 33 & $5^{\mathrm{h}} 4^{\mathrm{m}} \cdot 3$ & $-68^{\circ} 36^{\prime}$ & 37 & 1.1 & 160 & \\
\hline 43 & LMC N J0503-6643 & II & $5^{\mathrm{h}} 3^{\mathrm{m}} \cdot 4$ & $-66^{\circ} 48^{\prime}$ & 33 & $5^{\mathrm{h}} 3^{\mathrm{m}} \cdot 4$ & $-66^{\circ} 50^{\prime}$ & 24 & 1.2 & 26 & \\
\hline 45 & LMC N J0503-6719 & III & $5^{\mathrm{h}} 3^{\mathrm{m}} \cdot 7$ & $-67^{\circ} 24^{\prime}$ & 44 & $5^{\mathrm{h}} 3^{\mathrm{m}} \cdot 7$ & $-67^{\circ} 24^{\prime}$ & 24 & 2.0 & 0 & \\
\hline 46 & LMC N J0504-6802 & III & $5^{\mathrm{h}} 4^{\mathrm{m}} \cdot 6$ & $-68^{\circ} 6^{\prime}$ & 47 & $5^{\mathrm{h}} 4^{\mathrm{m}} \cdot 3$ & $-68^{\circ} 8^{\prime}$ & 18 & 1.0 & 83 & \\
\hline 48 & LMC N J0504-7007 & II & $5^{\mathrm{h}} 5^{\mathrm{m}}$ & $-70^{\circ} 12^{\prime}$ & 44 & $5^{\mathrm{h}} 5^{\mathrm{m}} \cdot 1$ & $-70^{\circ} 12^{\prime}$ & 8 & 1.4 & 0 & \\
\hline 49 & LMC N J0504-7056 & III & $5^{\mathrm{h}} 5^{\mathrm{m}} \cdot 3$ & $-71^{\circ} 0^{\prime}$ & 52 & $5^{\mathrm{h}} 5^{\mathrm{m}} \cdot 3$ & $-71^{\circ} 0^{\prime}$ & 34 & 1.0 & 0 & \\
\hline 52 & LMC N J0506-6753 & II & $5^{\mathrm{h}} 6^{\mathrm{m}} \cdot 8$ & $-67^{\circ} 58^{\prime}$ & 23 & $5^{\mathrm{h}} 7^{\mathrm{m}} \cdot 2$ & $-67^{\circ} 56^{\prime}$ & 24 & 1.0 & 83 & \\
\hline 53 & LMC N J0507-7041 & II & $5^{\mathrm{h}} 7^{\mathrm{m}} \cdot 9$ & $-70^{\circ} 46^{\prime}$ & 23 & $5^{\mathrm{h}} 7^{\mathrm{m}} \cdot 8$ & $-70^{\circ} 48^{\prime}$ & 24 & 0.9 & 28 & \\
\hline 55 & LMC N J0507-6858 & I & $5^{\mathrm{h}} 8^{\mathrm{m}} \cdot 1$ & $-69^{\circ} 2^{\prime}$ & 47 & $5^{\mathrm{h}} 8^{\mathrm{m}} \cdot 1$ & $-69^{\circ} 0^{\prime}$ & 29 & 1.3 & 28 & \\
\hline 57 & LMC N J0508-6905 & I & $5^{\mathrm{h}} 9^{\mathrm{m}} \cdot 1$ & $-69^{\circ} 8^{\prime}$ & 23 & $5^{\mathrm{h}} 9^{\mathrm{m}} \cdot 2$ & $-60^{\circ} 8^{\prime}$ & 8 & 1.0 & 0 & \\
\hline 60 & LMC N J0509-6827 & II & $5^{\mathrm{h}} 9^{\mathrm{m}} \cdot 4$ & $-68^{\circ} 32^{\prime}$ & 33 & $5^{\mathrm{h}} 9^{\mathrm{m}} \cdot 5$ & $-68^{\circ} 30^{\prime}$ & 47 & 1.6 & 26 & \\
\hline 61 & LMC N J0509-7049 & II & $5^{\mathrm{h}} 10^{\mathrm{m}} \cdot 2$ & $-70^{\circ} 54^{\prime}$ & 29 & $5^{\text {h }} 9^{\mathrm{m}} \cdot 8$ & $-70^{\circ} 54^{\prime}$ & 8 & 1.0 & 87 & \\
\hline 62 & LMC N J0509-6912 & I & $5^{\mathrm{h}} 10^{\mathrm{m}} \cdot 2$ & $-69^{\circ} 16^{\prime}$ & 52 & $5^{\mathrm{h}} 10^{\mathrm{m}} \cdot 6$ & $-69^{\circ} 16^{\prime}$ & 37 & 1.7 & 79 & \\
\hline 63 & LMC N J0510-6853 & III & $5^{\mathrm{h}} 10^{\mathrm{m}} \cdot 4$ & $-68^{\circ} 56^{\prime}$ & 84 & $5^{\mathrm{h}} 10^{\mathrm{m}}$ & $-68^{\circ} 52^{\prime}$ & 77 & 2.3 & 93 & 245,68 \\
\hline 64 & LMC N J0510-6706 & II & $5^{\mathrm{h}} 10^{\mathrm{m}} \cdot 7$ & $-67^{\circ} 12^{\prime}$ & 52 & $5^{\mathrm{h}} 11^{\mathrm{m}} \cdot 1$ & $-66^{\circ} 58^{\prime}$ & 74 & 1.2 & 222 & 67 \\
\hline 65 & LMC N J0511-6927 & II & $5^{\mathrm{h}} 11^{\mathrm{m}} \cdot 6$ & $-69^{\circ} 30^{\prime}$ & 23 & $5^{\mathrm{h}} 12^{\mathrm{m}}$ & $-69^{\circ} 32^{\prime}$ & 47 & 0.8 & 83 & 244,71 \\
\hline 67 & LMC N J0512-6710 & II & $5^{\mathrm{h}} 12^{\mathrm{m}} \cdot 1$ & $-67^{\circ} 14^{\prime}$ & 55 & $5^{\mathrm{h}} 12^{\mathrm{m}} \cdot 4$ & $-67^{\circ} 14^{\prime}$ & 55 & 1.6 & 79 & 64 \\
\hline 68 & LMC N J0512-6903 & II & $5^{\mathrm{h}} 12^{\mathrm{m}} \cdot 2$ & $-69^{\circ} 4^{\prime}$ & 80 & $5^{\mathrm{h}} 11^{\mathrm{m}} \cdot 4$ & $-69^{\circ} 4^{\prime}$ & 88 & 1.8 & 166 & 63 \\
\hline 69 & LMC N J0512-7028 & II & $5^{\mathrm{h}} 12^{\mathrm{m}} \cdot 8$ & $-70^{\circ} 32^{\prime}$ & 68 & $5^{\mathrm{h}} 12^{\mathrm{m}} \cdot 8$ & $-70^{\circ} 30^{\prime}$ & 50 & 1.5 & 26 & \\
\hline 71 & LMC N J0513-6936 & II & $5^{\mathrm{h}} 13^{\mathrm{m}} \cdot 5$ & $-69^{\circ} 40^{\prime}$ & 79 & $5^{\mathrm{h}} 13^{\mathrm{m}} \cdot 5$ & $-69^{\circ} 44^{\prime}$ & 59 & 1.9 & 62 & \\
\hline 72 & LMC N J0513-6922 & III & $5^{\mathrm{h}} 13^{\mathrm{m}} \cdot 5$ & $-69^{\circ} 26^{\prime}$ & 49 & $5^{\mathrm{h}} 13^{\mathrm{m}} \cdot 2$ & $-69^{\circ} 24^{\prime}$ & 34 & 1.7 & 83 & \\
\hline 74 & LMC N J0514-7010 & II & $5^{\mathrm{h}} 14^{\mathrm{m}} \cdot 9$ & $-70^{\circ} 14^{\prime}$ & 66 & $5^{\mathrm{h}} 14^{\mathrm{m}} \cdot 9$ & $-70^{\circ} 14^{\prime}$ & 34 & 1.6 & 0 & \\
\hline 77 & LMC N J0515-7034 & I & $5^{\mathrm{h}} 15^{\mathrm{m}} \cdot 6$ & $-70^{\circ} 38^{\prime}$ & 44 & $5^{\mathrm{h}} 15^{\mathrm{m}} \cdot 6$ & $-70^{\circ} 38^{\prime}$ & 18 & 0.6 & 0 & \\
\hline 80 & LMC N J0516-6807 & II & $5^{\mathrm{h}} 16^{\mathrm{m}} \cdot 1$ & $-68^{\circ} 2^{\prime}$ & 124 & $5^{\mathrm{h}} 17^{\mathrm{m}} \cdot 2$ & $-68^{\circ} 4^{\prime}$ & 62 & 1.4 & 237 & \\
\hline 81 & LMC N J0516-6616 & I & $5^{\mathrm{h}} 16^{\mathrm{m}}$ & $-66^{\circ} 20^{\prime}$ & 29 & $5^{\mathrm{h}} 16^{\mathrm{m}}$ & $-66^{\circ} 18^{\prime}$ & 24 & 0.3 & 26 & \\
\hline 83 & LMC N J0516-6922 & II & $5^{\mathrm{h}} 17^{\mathrm{m}}$ & $-69^{\circ} 26^{\prime}$ & 23 & $5^{\mathrm{h}} 17^{\mathrm{m}} \cdot 4$ & $-69^{\circ} 26^{\prime}$ & 34 & 1.3 & 87 & 91 \\
\hline 84 & LMC N J0516-6559 & II & $5^{\mathrm{h}} 16^{\mathrm{m}} \cdot 7$ & $-66^{\circ} 2^{\prime}$ & 29 & $5^{\mathrm{h}} 17^{\mathrm{m}} \cdot 1$ & $-66^{\circ} 2^{\prime}$ & 29 & 0.6 & 70 & \\
\hline 86 & LMC N J0517-7114 & III & $5^{\mathrm{h}} 18^{\mathrm{m}} \cdot 3$ & $-71^{\circ} 18^{\prime}$ & 44 & $5^{\mathrm{h}} 18^{\mathrm{m}} \cdot 3$ & $-71^{\circ} 20^{\prime}$ & 37 & 1.3 & 26 & \\
\hline 89 & LMC N J0517-6642 & II & $5^{\mathrm{h}} 17^{\mathrm{m}} \cdot 6$ & $-66^{\circ} 44^{\prime}$ & 40 & $5^{\mathrm{h}} 17^{\mathrm{m}} \cdot 6$ & $-66^{\circ} 44^{\prime}$ & 18 & 0.9 & 0 & \\
\hline 90 & LMC N J0517-6932 & II & $5^{\mathrm{h}} 18^{\mathrm{m}} \cdot 5$ & $-69^{\circ} 36^{\prime}$ & 33 & $5^{\mathrm{h}} 18^{\mathrm{m}} \cdot 5$ & $-69^{\circ} 36^{\prime}$ & $*$ & 0.9 & 0 & \\
\hline 92 & LMC N J0518-7001 & I & $5^{\mathrm{h}} 18^{\mathrm{m}} \cdot 8$ & $-70^{\circ} 6^{\prime}$ & 33 & $5^{\mathrm{h}} 18^{\mathrm{m}} \cdot 1$ & $-70^{\circ} 4^{\prime}$ & 18 & 1.1 & 168 & \\
\hline 93 & LMC N J0518-6620 & I & $5^{\mathrm{h}} 18^{\mathrm{m}} \cdot 3$ & $-66^{\circ} 24^{\prime}$ & 23 & $5^{\mathrm{h}} 18^{\mathrm{m}}$ & $-66^{\circ} 22^{\prime}$ & $*$ & 0.5 & 75 & \\
\hline 94 & LMC N J0518-6951 & II & $5^{\mathrm{h}} 19^{\mathrm{m}} \cdot 2$ & $-69^{\circ} 54^{\prime}$ & 23 & $5^{\mathrm{h}} 19^{\mathrm{m}} \cdot 2$ & $-69^{\circ} 56^{\prime}$ & 24 & 0.9 & 26 & \\
\hline 95 & LMC N J0519-6625 & I & $5^{\mathrm{h}} 19^{\mathrm{m}}$ & $-66^{\circ} 28^{\prime}$ & 23 & $5^{\mathrm{h}} 19^{\mathrm{m}}$ & $-66^{\circ} 30^{\prime}$ & $*$ & 1.2 & 26 & 100 \\
\hline 96 & LMC N J0519-6938 & III & $5^{\mathrm{h}} 19^{\mathrm{m}} \cdot 6$ & $-69^{\circ} 40^{\prime}$ & 72 & $5^{\mathrm{h}} 19^{\mathrm{m}} \cdot 6$ & $-69^{\circ} 40^{\prime}$ & 29 & 2.0 & 0 & \\
\hline 97 & LMC N J0519-7113 & I & $5^{\mathrm{h}} 20^{\mathrm{m}}$ & $-71^{\circ} 18^{\prime}$ & 40 & $5^{\mathrm{h}} 20^{\mathrm{m}} \cdot 4$ & $-71^{\circ} 16^{\prime}$ & 24 & 0.9 & 91 & \\
\hline 99 & LMC N J0520-7043 & I & $5^{\mathrm{h}} 20^{\mathrm{m}} \cdot 4$ & $-70^{\circ} 44^{\prime}$ & 52 & $5^{\mathrm{h}} 20^{\mathrm{m}}$ & $-70^{\circ} 46^{\prime}$ & 37 & 1.0 & 91 & \\
\hline 100 & LMC N J0520-665 & II & $5^{\mathrm{h}} 20^{\mathrm{m}}$ & $-66^{\circ} 54^{\prime}$ & 37 & $5^{\mathrm{h}} 21^{\mathrm{m}}$ & $-66^{\circ} 50^{\prime}$ & 52 & 1.3 & 226 & \\
\hline 103 & LMC N J0521-714 & II & $5^{\mathrm{h}} 21^{\mathrm{m}} \cdot 7$ & $-71^{\circ} 46^{\prime}$ & 23 & $5^{\mathrm{h}} 21^{\mathrm{m}} \cdot 7$ & $-71^{\circ} 46^{\prime}$ & 24 & 1.2 & 0 & \\
\hline 104 & LMC N J0521-701 & II & $5^{\mathrm{h}} 21^{\mathrm{m}} \cdot 6$ & $-70^{\circ} 16^{\prime}$ & 49 & $5^{\mathrm{h}} 21^{\mathrm{m}} \cdot 2$ & $-70^{\circ} 18^{\prime}$ & 29 & 0.8 & 91 & \\
\hline 105 & LMC N J0521-700 & II & $5^{\mathrm{h}} 21^{\mathrm{m}} \cdot 6$ & $-70^{\circ} 4^{\prime}$ & 79 & $5^{\mathrm{h}} 21^{\mathrm{m}} \cdot 6$ & $-70^{\circ} 6^{\prime}$ & 44 & 1.4 & 26 & \\
\hline 106 & LMC N J0521-684 & II & $5^{\mathrm{h}} 21^{\mathrm{m}} \cdot 5$ & $-68^{\circ} 44^{\prime}$ & 29 & $5^{\mathrm{h}} 21^{\mathrm{m}} \cdot 5$ & $-68^{\circ} 44^{\prime}$ & 8 & 1.7 & 0 & \\
\hline 108 & LMC N J0521-684 & II & $5^{\mathrm{h}} 21^{\mathrm{m}} \cdot 8$ & $-68^{\circ} 50^{\prime}$ & 55 & $5^{\mathrm{h}} 21^{\mathrm{m}} \cdot 8$ & $-68^{\circ} 50^{\prime}$ & 34 & 1.4 & 0 & \\
\hline 110 & LMC N J0522-694 & III & $5^{\mathrm{h}} 22^{\mathrm{m}} \cdot 7$ & $-69^{\circ} 44^{\prime}$ & 52 & $5^{\mathrm{h}} 22^{\mathrm{m}} \cdot 3$ & $-69^{\circ} 44^{\prime}$ & 18 & 1.2 & 79 & \\
\hline 115 & LMC N J0522-654 & III & $5^{\mathrm{h}} 22^{\mathrm{m}} \cdot 6$ & $-65^{\circ} 44^{\prime}$ & 57 & $5^{\mathrm{h}} 22^{\mathrm{m}} \cdot 6$ & $-65^{\circ} 42^{\prime}$ & 44 & 1.7 & 26 & \\
\hline 118 & LMC N J0523-682 & I & $5^{\mathrm{h}} 22^{\mathrm{m}} \cdot 9$ & $-68^{\circ} 24^{\prime}$ & 44 & $5^{\mathrm{h}} 22^{\mathrm{m}} \cdot 9$ & $-68^{\circ} 26^{\prime}$ & 37 & 3.2 & 26 & \\
\hline 119 & LMC N J0523-664 & II & $5^{\mathrm{h}} 23^{\mathrm{m}}$ & $-66^{\circ} 46^{\prime}$ & 57 & $5^{\mathrm{h}} 22^{\mathrm{m}} \cdot 7$ & $-66^{\circ} 46^{\prime}$ & 41 & 2.5 & 79 & \\
\hline 123 & LMC N J0523-713 & II & $5^{\mathrm{h}} 24^{\mathrm{m}} \cdot 2$ & $-71^{\circ} 42^{\prime}$ & 49 & $5^{\mathrm{h}} 26^{\mathrm{m}} \cdot 4$ & $-71^{\circ} 38^{\prime}$ & 62 & 1.4 & 466 & 131,249 \\
\hline 126 & LMC N J0524-672 & II & $5^{\mathrm{h}} 24^{\mathrm{m}} \cdot 5$ & $-67^{\circ} 30^{\prime}$ & 44 & $5^{\mathrm{h}} 24^{\mathrm{m}} \cdot 5$ & $-67^{\circ} 30^{\prime}$ & 24 & 2.3 & 0 & \\
\hline
\end{tabular}


Table 2

(Continued)

\begin{tabular}{|c|c|c|c|c|c|c|c|c|c|c|c|}
\hline \multirow[t]{2}{*}{ Number $^{\mathrm{a}}$} & \multirow[t]{2}{*}{ Name $^{\mathrm{a}}$} & \multirow[t]{2}{*}{ Type $^{\text {b }}$} & \multicolumn{2}{|c|}{ Peak Position $(\mathrm{CO})^{\mathrm{c}}$} & \multirow{2}{*}{$\begin{array}{c}R(\mathrm{CO})^{\mathrm{a}} \\
(\mathrm{pc})\end{array}$} & \multicolumn{2}{|c|}{ Peak Position $\left(\mathrm{HI}_{\mathrm{I}}\right)^{\mathrm{c}}$} & \multirow{2}{*}{$\begin{array}{c}R\left(\mathrm{H} \mathrm{I}^{\mathrm{d}}\right. \\
\quad(\mathrm{pc})\end{array}$} & \multirow{2}{*}{$\begin{array}{c}N(\mathrm{H} \mathrm{I})^{\mathrm{e}} \\
10^{21}\left(\mathrm{~cm}^{-2}\right)\end{array}$} & \multirow{2}{*}{$\begin{array}{c}\sqrt{\Delta \alpha^{2}+\Delta \delta^{2}} \mathrm{f} \\
(\mathrm{pc})\end{array}$} & \multirow[t]{2}{*}{ Comment $^{\mathrm{g}}$} \\
\hline & & & $\alpha(B 1950)$ & $\delta(B 1950)$ & & $\alpha(B 1950)$ & $\delta(B 1950)$ & & & & \\
\hline 127 & LMC N J0524-702 & I & $5^{\mathrm{h}} 24^{\mathrm{m}} \cdot 8$ & $-70^{\circ} 30^{\prime}$ & 37 & $5^{\mathrm{h}} 24^{\mathrm{m}} \cdot 4$ & $-70^{\circ} 30^{\prime}$ & 24 & 0.6 & 87 & \\
\hline 130 & LMC N J0524-691 & II & $5^{\mathrm{h}} 24^{\mathrm{m}} \cdot 9$ & $-69^{\circ} 18^{\prime}$ & 33 & $5^{\mathrm{h}} 24^{\mathrm{m}} .5$ & $-69^{\circ} 12^{\prime}$ & 47 & 1.2 & 123 & \\
\hline 131 & LMC N J0524-713 & II & $5^{\mathrm{h}} 25^{\mathrm{m}} \cdot 5$ & $-71^{\circ} 36^{\prime}$ & 29 & $5^{\mathrm{h}} 25^{\mathrm{m}} \cdot 9$ & $-71^{\circ} 38^{\prime}$ & 64 & 1.7 & 99 & 123,249 \\
\hline 132 & LMC N J0525-694 & II & $5^{\mathrm{h}} 26^{\mathrm{m}} \cdot 2$ & $-69^{\circ} 52^{\prime}$ & 33 & $5^{\mathrm{h}} 25^{\mathrm{m}} \cdot 8$ & $-69^{\circ} 56^{\prime}$ & 34 & 1.0 & 99 & \\
\hline 133 & LMC N J0525-691 & III & $5^{\mathrm{h}} 26^{\mathrm{m}}$ & $-69^{\circ} 20^{\prime}$ & 33 & $5^{\mathrm{h}} 24^{\mathrm{m}} \cdot 5$ & $-69^{\circ} 12^{\prime}$ & 47 & 0.8 & 359 & 130 \\
\hline 134 & LMC N J0525-662 & II & $5^{\mathrm{h}} 25^{\mathrm{m}} \cdot 7$ & $-66^{\circ} 24^{\prime}$ & 23 & $5^{\mathrm{h}} 25^{\mathrm{m}} \cdot 3$ & $-66^{\circ} 26^{\prime}$ & 116 & 3.8 & 75 & 135 \\
\hline 136 & LMC N J0526-683 & II & $5^{\mathrm{h}} 26^{\mathrm{m}} \cdot 2$ & $-68^{\circ} 38^{\prime}$ & 37 & $5^{\mathrm{h}} 26^{\mathrm{m}} \cdot 2$ & $-68^{\circ} 38^{\prime}$ & 41 & 1.4 & 0 & \\
\hline 139 & LMC N J0526-684 & III & $5^{\mathrm{h}} 26^{\mathrm{m}} \cdot 6$ & $-68^{\circ} 50^{\prime}$ & 29 & $5^{\mathrm{h}} 26^{\mathrm{m}} \cdot 3$ & $-68^{\circ} 48^{\prime}$ & 29 & 1.9 & 91 & \\
\hline 141 & LMC N J0526-655 & II & $5^{\mathrm{h}} 26^{\mathrm{m}} \cdot 5$ & $-65^{\circ} 56^{\prime}$ & 23 & $5^{\mathrm{h}} 26^{\mathrm{m}} \cdot 2$ & $-66^{\circ} 0^{\prime}$ & 160 & 2.0 & 93 & $134,135,250$ \\
\hline 143 & LMC N J0526-711 & II & $5^{\mathrm{h}} 27^{\mathrm{m}} \cdot 5$ & $-71^{\circ} 22^{\prime}$ & 97 & $5^{\mathrm{h}} 26^{\mathrm{m}}$ & $-71^{\circ} 26^{\prime}$ & 120 & 1.3 & 346 & 153,156 \\
\hline 145 & LMC N J0527-703 & II & $5^{\mathrm{h}} 28^{\mathrm{m}}$ & $-70^{\circ} 38^{\prime}$ & 40 & $5^{\mathrm{h}} 28^{\mathrm{m}} \cdot 1$ & $-70^{\circ} 40^{\prime}$ & 18 & 0.6 & 26 & \\
\hline 146 & LMC N J0527-705 & II & $5^{\mathrm{h}} 28^{\mathrm{m}} \cdot 6$ & $-70^{\circ} 54^{\prime}$ & 37 & $5^{\mathrm{h}} 28^{\mathrm{m}} \cdot 6$ & $-70^{\circ} 54^{\prime}$ & 72 & 1.0 & 0 & 149 \\
\hline 149 & LMC N J0528-705 & II & $5 \mathrm{~h} 29 \mathrm{~m}$ & $-71^{\circ} 0^{\prime}$ & 33 & $5^{\mathrm{h}} 29^{\mathrm{m}} \cdot 4$ & $-71^{\circ} 0^{\prime}$ & 24 & 1.7 & 87 & \\
\hline 150 & LMC N J0529-683 & II & $5^{\mathrm{h}} 30^{\mathrm{m}} \cdot 2$ & $-68^{\circ} 32^{\prime}$ & 29 & $5^{\mathrm{h}} 30^{\mathrm{m}} \cdot 6$ & $-68^{\circ} 36^{\prime}$ & 142 & 1.8 & 106 & 154,163 \\
\hline 153 & LMC N J0530-710 & III & $5^{\mathrm{h}} 31^{\mathrm{m}} \cdot 6$ & $-71^{\circ} 10^{\prime}$ & 80 & $5^{\mathrm{h}} 31^{\mathrm{m}} \cdot 6$ & $-71^{\circ} 10^{\prime}$ & 47 & 2.6 & 0 & \\
\hline 154 & LMC N J0531-683 & III & $5^{\mathrm{h}} 31^{\mathrm{m}} .7$ & $-68^{\circ} 34^{\prime}$ & 108 & $5^{\mathrm{h}} 32^{\mathrm{m}} .7$ & $-68^{\circ} 28^{\prime}$ & 55 & 2.7 & 243 & 150,163 \\
\hline 155 & LMC N J0532-674 & III & $5^{\mathrm{h}} 32^{\mathrm{m}}$ & $-67^{\circ} 46^{\prime}$ & 68 & $5^{\mathrm{h}} 32^{\mathrm{m}} \cdot 7$ & $-67^{\circ} 46^{\prime}$ & 44 & 3.1 & 157 & \\
\hline 156 & LMC N J0532-711 & II & $5^{\mathrm{h}} 32^{\mathrm{m}} \cdot 9$ & $-71^{\circ} 16^{\prime}$ & 47 & $5^{\mathrm{h}} 32^{\mathrm{m}} \cdot 9$ & $-71^{\circ} 16^{\prime}$ & 41 & 2.5 & 0 & \\
\hline 157 & LMC N J0532-683 & II & $5^{\mathrm{h}} 32^{\mathrm{m}} \cdot 5$ & $-68^{\circ} 40^{\prime}$ & 40 & $5^{\mathrm{h}} 32^{\mathrm{m}} \cdot 5$ & $-68^{\circ} 40^{\prime}$ & 41 & 2.7 & 0 & \\
\hline 158 & LMC N J0532-662 & III & $5^{\mathrm{h}} 32^{\mathrm{m}} \cdot 4$ & $-66^{\circ} 30^{\prime}$ & 47 & $5^{\mathrm{h}} 32^{\mathrm{m}}$ & $-66^{\circ} 26^{\prime}$ & 29 & 0.9 & 99 & \\
\hline 162 & LMC N J0532-685 & II & $5^{\mathrm{h}} 33^{\mathrm{m}} \cdot 4$ & $-69^{\circ} 0^{\prime}$ & 33 & $5^{\mathrm{h}} 33^{\mathrm{m}}$ & $-69^{\circ} 0^{\prime}$ & 18 & 2.4 & 79 & \\
\hline 171 & LMC N J0535-690 & III & $5^{\mathrm{h}} 36^{\mathrm{m}}$ & $-69^{\circ} 4^{\prime}$ & 66 & $5^{\mathrm{h}} 36^{\mathrm{m}} \cdot 4$ & $-69^{\circ} 4^{\prime}$ & 91 & 3.5 & 79 & 183 \\
\hline 172 & LMC N J0535-684 & II & $5^{\mathrm{h}} 36^{\mathrm{m}} \cdot 2$ & $-68^{\circ} 46^{\prime}$ & 37 & $5^{\mathrm{h}} 35^{\mathrm{m}} .8$ & $-68^{\circ} 46^{\prime}$ & 41 & 1.6 & 79 & \\
\hline 179 & LMC N J0537-661 & III & $5^{\mathrm{h}} 37^{\mathrm{m}} \cdot 3$ & $-66^{\circ} 20^{\prime}$ & 47 & $5^{\mathrm{h}} 37^{\mathrm{m}} \cdot 3$ & $-66^{\circ} 20^{\prime}$ & 44 & 2.1 & 0 & \\
\hline 180 & LMC N J0537-662 & II & $5^{\mathrm{h}} 37^{\mathrm{m}} \cdot 4$ & $-66^{\circ} 28^{\prime}$ & 23 & $5^{\mathrm{h}} 37^{\mathrm{m}} \cdot 1$ & $-66^{\circ} 30^{\prime}$ & 34 & 1.8 & 75 & \\
\hline 184 & LMC N J0538-693 & II & $5^{\mathrm{h}} 38^{\mathrm{m}} .7$ & $-69^{\circ} 36^{\prime}$ & 33 & $5^{\mathrm{h}} 39^{\mathrm{m}} \cdot 1$ & $-69^{\circ} 34^{\prime}$ & 41 & 3.5 & 83 & 191 \\
\hline 190 & LMC N J0538-685 & III & $5^{\mathrm{h}} 38^{\mathrm{m}} \cdot 9$ & $-68^{\circ} 56^{\prime}$ & 23 & $5^{\mathrm{h}} 41^{\mathrm{m}} \cdot 1$ & $-68^{\circ} 54^{\prime}$ & 81 & 2.9 & 480 & \\
\hline 191 & LMC N J0539-693 & III & $5^{\mathrm{h}} 39^{\mathrm{m}} \cdot 4$ & $-69^{\circ} 32^{\prime}$ & 57 & $5^{\mathrm{h}} 39^{\mathrm{m}} \cdot 1$ & $-69^{\circ} 34^{\prime}$ & 41 & 3.5 & 83 & 184 \\
\hline 205 & LMC N J0542-711 & III & $5^{\mathrm{h}} 42^{\mathrm{m}} \cdot 1$ & $-71^{\circ} 20^{\prime}$ & 64 & $5^{\mathrm{h}} 42^{\mathrm{m}}$ & $-71^{\circ} 18^{\prime}$ & 47 & 2.5 & 28 & \\
\hline 207 & LMC N J0542-694 & II & $5^{\mathrm{h}} 43^{\mathrm{m}} \cdot 5$ & $-69^{\circ} 46^{\prime}$ & 23 & $5^{\mathrm{h}} 43^{\mathrm{m}} \cdot 5$ & $-69^{\circ} 46^{\prime}$ & 18 & 4.1 & 0 & 266 \\
\hline 208 & LMC N J0543-675 & III & $5^{\mathrm{h}} 43^{\mathrm{m}} \cdot 5$ & $-67^{\circ} 58^{\prime}$ & 37 & $5^{\mathrm{h}} 43^{\mathrm{m}} \cdot 8$ & $-67^{\circ} 58^{\prime}$ & 34 & 2.0 & 79 & 211 \\
\hline 209 & LMC N J0543-692 & II & $5^{\mathrm{h}} 43^{\mathrm{m}} \cdot 9$ & $-69^{\circ} 28^{\prime}$ & 33 & $5^{\mathrm{h}} 44^{\mathrm{m}} \cdot 2$ & $-69^{\circ} 22^{\prime}$ & 47 & 3.0 & 106 & $214,216,268$ \\
\hline 211 & LMC N J0543-675 & III & $5^{\mathrm{h}} 43^{\mathrm{m}} \cdot 8$ & $-67^{\circ} 56^{\prime}$ & 23 & $5^{\mathrm{h}} 43^{\mathrm{m}} \cdot 8$ & $-67^{\circ} 58^{\prime}$ & 29 & 1.8 & 28 & 208 \\
\hline 214 & LMC N J0543-691 & II & $5^{\mathrm{h}} 43^{\mathrm{m}} \cdot 4$ & $-69^{\circ} 16^{\prime}$ & 33 & $5^{\mathrm{h}} 44^{\mathrm{m}} \cdot 2$ & $-69^{\circ} 22^{\prime}$ & 44 & 2.5 & 211 & $209,216,268$ \\
\hline 215 & LMC N J0544-712 & I & $5^{\mathrm{h}} 45^{\mathrm{m}} \cdot 2$ & $-71^{\circ} 28^{\prime}$ & 59 & $5^{\mathrm{h}} 44^{\mathrm{m}} \cdot 7$ & $-71^{\circ} 28^{\prime}$ & 57 & 1.9 & 87 & \\
\hline 218 & LMC N J0544-671 & II & $5^{\mathrm{h}} 44^{\mathrm{m}} \cdot 9$ & $-67^{\circ} 20^{\prime}$ & 29 & $5^{\mathrm{h}} 44^{\mathrm{m}} .4$ & $-67^{\circ} 28^{\prime}$ & 50 & 1.0 & 167 & 213 \\
\hline 220 & LMC N J0545-694 & III & $5^{\mathrm{h}} 45^{\mathrm{m}} \cdot 9$ & $-69^{\circ} 50^{\prime}$ & 47 & $5^{\mathrm{h}} 45^{\mathrm{m}} \cdot 6$ & $-69^{\circ} 52^{\prime}$ & 37 & 2.0 & 83 & \\
\hline 222 & LMC N J0546-710 & I & $5^{\mathrm{h}} 46^{\mathrm{m}} \cdot 8$ & $-71^{\circ} 6^{\prime}$ & 44 & $5^{\mathrm{h}} 46^{\mathrm{m}} \cdot 8$ & $-71^{\circ} 6^{\prime}$ & 44 & 1.7 & 0 & \\
\hline 223 & LMC N J0546-693 & II & $5^{\mathrm{h}} 46^{\mathrm{m}} \cdot 8$ & $-69^{\circ} 38^{\prime}$ & 52 & $5^{\mathrm{h}} 47^{\mathrm{m}} \cdot 2$ & $-69^{\circ} 40^{\prime}$ & 57 & 3.3 & 99 & \\
\hline 224 & LMC N J0547-680 & I & $5^{\mathrm{h}} 47^{\mathrm{m}} \cdot 6$ & $-68^{\circ} 10^{\prime}$ & 33 & $5^{\mathrm{h}} 48^{\mathrm{m}}$ & $-68^{\circ} 10^{\prime}$ & 55 & 1.7 & 79 & \\
\hline 225 & LMC N J0547-704 & I & $5^{\mathrm{h}} 47^{\mathrm{m}} .8$ & $-70^{\circ} 42^{\prime}$ & 87 & $5^{\mathrm{h}} 47^{\mathrm{m}} .8$ & $-70^{\circ} 40^{\prime}$ & $*$ & 1.3 & 28 & 228 \\
\hline 226 & LMC N J0547-6953 & II & $5^{\mathrm{h}} 48^{\mathrm{m}} \cdot 7$ & $-69^{\circ} 54^{\prime}$ & 61 & $5^{\mathrm{h}} 48^{\mathrm{m}}$ & $-69^{\circ} 56^{\prime}$ & 104 & 1.6 & 159 & $223,227,270$ \\
\hline 230 & LMC N J0555-681 & III & $5^{\mathrm{h}} 55^{\mathrm{m}} \cdot 9$ & $-68^{\circ} 10^{\prime}$ & 73 & $5^{\mathrm{h}} 55^{\mathrm{m}} \cdot 9$ & $-68^{\circ} 10^{\prime}$ & $*$ & 1.3 & 0 & 271 \\
\hline 231 & LMC N J0447-672 & I & $4^{\mathrm{h}} 47^{\mathrm{m}} \cdot 2$ & $-67^{\circ} 34^{\prime}$ & 17 & $4^{\mathrm{h}} 47^{\mathrm{m}} \cdot 1$ & $-67^{\circ} 36^{\prime}$ & 190 & 1.2 & 28 & 2,232 \\
\hline 232 & LMC N J0448-672 & I & $4^{\mathrm{h}} 48^{\mathrm{m}}$ & $-67^{\circ} 28^{\prime}$ & 17 & $4^{\mathrm{h}} 47^{\mathrm{m}} \cdot 2$ & $-67^{\circ} 18^{\prime}$ & 82 & 1.2 & 229 & 2 \\
\hline 233 & LMC N J0449-681 & II & $4^{\mathrm{h}} 49^{\mathrm{m}} \cdot 8$ & $-68^{\circ} 16^{\prime}$ & 17 & $4^{\mathrm{h}} 49^{\mathrm{m}} \cdot 5$ & $-68^{\circ} 12^{\prime}$ & 88 & 1.3 & 86 & 6 \\
\hline 236 & LMC N J0458-661 & II & $4^{\mathrm{h}} 58^{\mathrm{m}} \cdot 7$ & $-66^{\circ} 22^{\prime}$ & 17 & $4^{\mathrm{h}} 58^{\mathrm{m}} \cdot 4$ & $-66^{\circ} 24^{\prime}$ & 75 & 3.7 & 83 & $30,32,33,35$ \\
\hline 237 & LMC N J0459-660 & II & $4^{\mathrm{h}} 59^{\mathrm{m}} .8$ & $-66^{\circ} 12^{\prime}$ & 17 & $5^{\mathrm{h}} 0^{\mathrm{m}} \cdot 2$ & $-66^{\circ} 12^{\prime}$ & $*$ & 2.7 & 70 & \\
\hline 243 & LMC N J0511-705 & I & $5^{\mathrm{h}} 12^{\mathrm{m}} \cdot 3$ & $-70^{\circ} 54^{\prime}$ & 17 & $5^{\mathrm{h}} 12^{\mathrm{m}} \cdot 7$ & $-70^{\circ} 54^{\prime}$ & 8 & 0.7 & 87 & \\
\hline 244 & LMC N J0511-692 & II & $5^{\mathrm{h}} 12^{\mathrm{m}}$ & $-69^{\circ} 32^{\prime}$ & 17 & $5^{\mathrm{h}} 12^{\mathrm{m}}$ & $-69^{\circ} 32^{\prime}$ & 29 & 1.1 & 0 & 65 \\
\hline 247 & LMC N J0521-673 & I & $5^{\mathrm{h}} 21^{\mathrm{m}} \cdot 8$ & $-67^{\circ} 42^{\prime}$ & 17 & $5^{\mathrm{h}} 22^{\mathrm{m}} \cdot 1$ & $-67^{\circ} 36^{\prime}$ & 34 & 0.9 & 117 & \\
\hline 252 & LMC N J0528-672 & III & $5^{\mathrm{h}} 28^{\mathrm{m}}$ & $-67^{\circ} 28^{\prime}$ & 17 & $5^{\mathrm{h}} 28^{\mathrm{m}}$ & $-67^{\circ} 28^{\prime}$ & 29 & 2.3 & 0 & \\
\hline 253 & LMC N J0530-675 & $\mathrm{I}$ & $5^{\mathrm{h}} 30^{\mathrm{m}} \cdot 7$ & $-68^{\circ} 0^{\prime}$ & 17 & $5^{\mathrm{h}} 31^{\mathrm{m}}$ & $-67^{\circ} 58^{\prime}$ & 47 & 2.1 & 83 & \\
\hline 258 & LMC N J0535-661 & II & $5^{\mathrm{h}} 35^{\mathrm{m}} \cdot 3$ & $-66^{\circ} 20^{\prime}$ & 17 & $5^{\mathrm{h}} 35^{\mathrm{m}} \cdot 3$ & $-66^{\circ} 18^{\prime}$ & 24 & 0.7 & 28 & \\
\hline 266 & LMC N J0543-694 & II & $5^{\mathrm{h}} 43^{\mathrm{m}} \cdot 6$ & $-69^{\circ} 48^{\prime}$ & 17 & $5^{\mathrm{h}} 43^{\mathrm{m}} \cdot 5$ & $-69^{\circ} 46^{\prime}$ & 18 & 3.6 & 28 & 207 \\
\hline 270 & LMC N J0547-695 & II & $5^{\mathrm{h}} 48^{\mathrm{m}} \cdot 1$ & $-70^{\circ} 0^{\prime}$ & 17 & $5^{\mathrm{h}} 48^{\mathrm{m}} \cdot 6$ & $-70^{\circ} 6^{\prime}$ & 82 & 2.0 & 143 & 226,227 \\
\hline 271 & LMC N J0553-682 & I & $5^{\mathrm{h}} 53^{\mathrm{m}} \cdot 3$ & $-68^{\circ} 24^{\prime}$ & 17 & $5^{\mathrm{h}} 53^{\mathrm{m}} \cdot 3$ & $-68^{\circ} 24^{\prime}$ & 55 & 1.9 & 0 & \\
\hline
\end{tabular}

Notes.

${ }^{\text {a }}$ Fukui et al. (2008).

${ }^{\mathrm{b}}$ Kawamura et al. (2009).

c Position of peak integrated intensity. Data are from Fukui et al. (2008).

${ }^{\mathrm{d}} \mathrm{H}$ I cloud radius defined as $R=\sqrt{\frac{S}{\pi}}$. Here $S$ is the cloud area, calculated by summing the areas of all pixels detected above $80 \%$ of the peak integrated intensity level. Asterisks show H i clouds whose extent is poorly defined.

${ }^{\mathrm{e}} \mathrm{H} \mathrm{I}$ column density of position at peak integrated intensity estimated by using the relation: $\left.N\left(\mathrm{HI}_{\mathrm{I}}\right)\left[\mathrm{cm}^{-2}\right]=1.82 \times 10^{18} \int T_{b}(\mathrm{H} \mathrm{I}) d v\left[\mathrm{~K} \mathrm{~km} \mathrm{~s}{ }^{-1}\right]\right)$.

${ }^{\mathrm{f}}$ Difference between $\mathrm{CO}$ peak position and $\mathrm{H}$ i peak position: $(\mathrm{CO}(\alpha, \delta)-\mathrm{H} \mathrm{I}(\alpha, \delta))$.

${ }^{\mathrm{g}} \mathrm{H}$ I clouds including two or more GMCs: the numbers show GMCs that are located in the same H i cloud. 

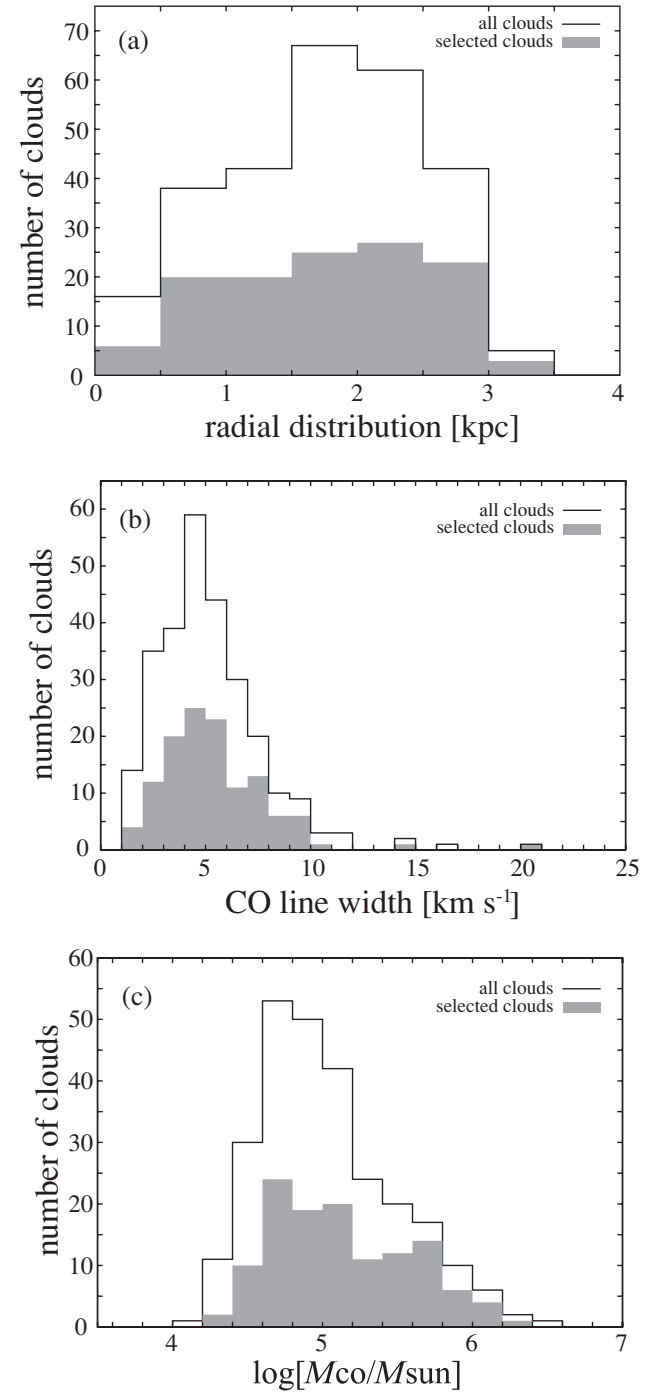

Figure 6. Histograms of three parameters: (a) the distance from the kinematic center of the galaxy $(\mathrm{kpc})$, (b) the CO line width $\left(\mathrm{km} \mathrm{s}^{-1}\right)$, and (c) the CO cloud mass $\left(M_{\odot}\right)$ for the 123 GMCs used in our analysis. The solid lines show the distribution of these properties for all the clouds in the Fukui et al. (2008) catalog; the gray shaded regions represent the distribution for the 123 selected GMCs (see also Table 2).

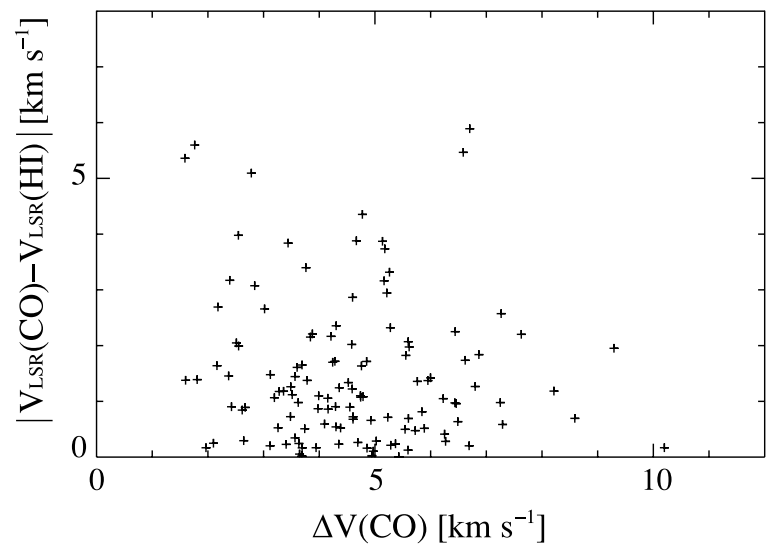

Figure 7. Absolute difference between the central velocity of the $\mathrm{HI}$ and $\mathrm{CO}$ emission, $\left|V_{\mathrm{LSR}}(\mathrm{CO})-V_{\mathrm{LSR}}(\mathrm{HI})\right|$, vs. the $\mathrm{CO}$ line width, $\Delta V(\mathrm{CO})$ for the 123 GMCs in our sample. The dotted line shows $\left|V_{\mathrm{LSR}}(\mathrm{CO})-V_{\mathrm{LSR}}(\mathrm{H} \mathrm{I})\right|=\Delta V(\mathrm{CO})$.

the enveloping $\mathrm{H}$ I gas accretes onto a GMC and that the GMC mass increases with time. The accreted $\mathrm{H}$ I envelope is converted

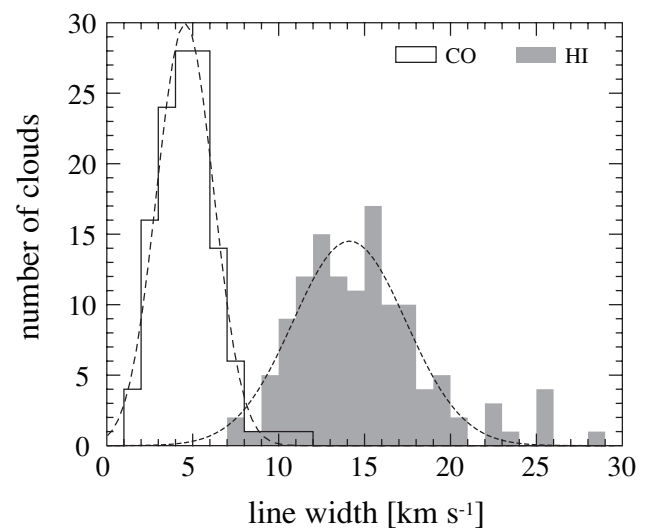

Figure 8. Histogram of the $\mathrm{CO}$ and $\mathrm{HI}$ line widths toward the position of the CO peak position for the 123 selected GMCs. The dotted lines show Gaussian fits to the histograms. The mean values (standard derivations) for the $\mathrm{CO}$ and $\mathrm{H}$ I distributions are $4.6(1.6)$ and $14.1(3.3) \mathrm{km} \mathrm{s}^{-1}$, respectively.

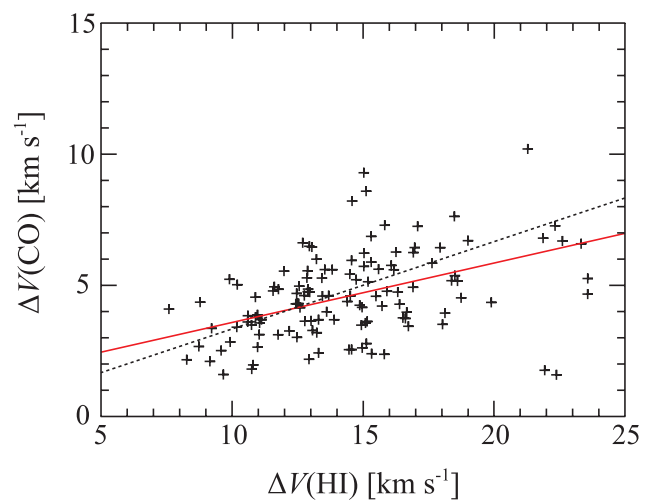

Figure 9. Plot of the $\mathrm{CO}$ vs. $\mathrm{H}$ I line width for the $123 \mathrm{GMCs}$ in our sample. The red line is the regression line $\Delta V(\mathrm{CO})=(1.32 \pm 0.04)+(0.23 \pm 0.003) \Delta V(\mathrm{HI})$, and the dotted line shows $\Delta V(\mathrm{H} \mathrm{I})=3 \times \Delta V(\mathrm{CO})$. The Spearman rank correlation coefficient is 0.39 .

(A color version of this figure is available in the online journal.)

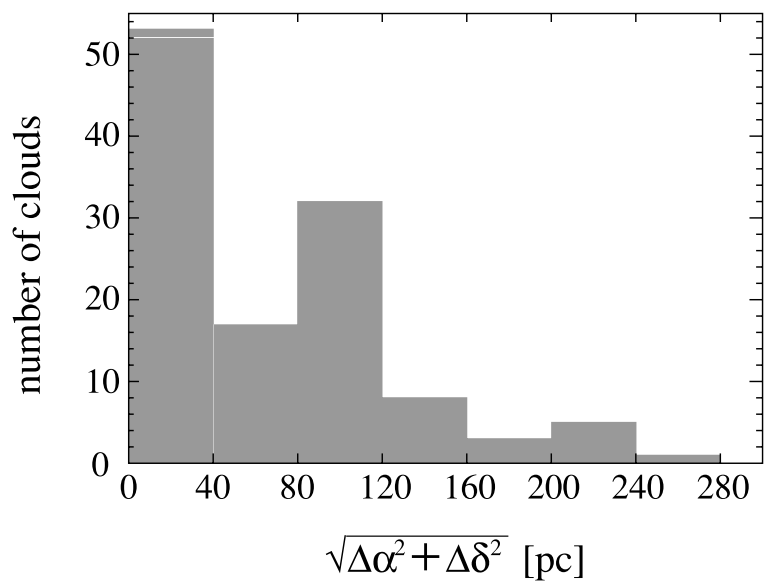

Figure 10. Histogram of the projected separation between the $\mathrm{CO}$ and $\mathrm{H}$ I peak positions, as listed in Table 2. The separation between the $\mathrm{CO}$ and $\mathrm{H}$ I peak positions for four of the 123 clouds is greater than $300 \mathrm{pc}$; these clouds are not shown.

into $\mathrm{H}_{2}$ in $\sim 10 \mathrm{Myr}$ due to increased density, optical extinction, and UV shielding. This infall scenario is consistent with the linear relationship between $I(\mathrm{HI})$ and $I(\mathrm{CO})$ in Figure 12; by contrast, growth of GMCs via collisions between H I clouds would have a steeper relationship, with $I(\mathrm{CO})$ proportional to $I(\mathrm{H} \mathrm{I})^{2}$. For an infall scenario, the infall motion can arise from the 


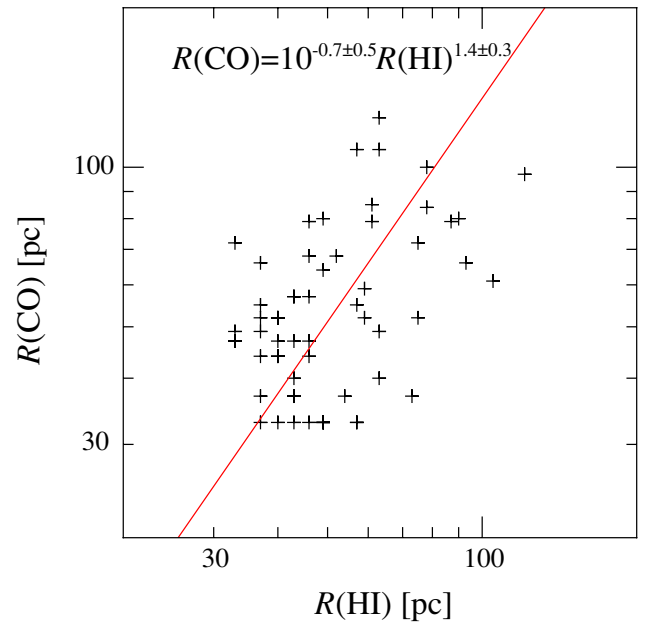

Figure 11. Radius of the GMC, $R(\mathrm{CO})$, vs. the radius of the $\mathrm{HI}$ envelope, $R(\mathrm{HI})$, for the 62 clouds with radii greater than $30 \mathrm{pc}$, as listed in Table 2 . The red line is the regression line $R(\mathrm{CO})=10^{-0.7 \pm 0.5} R(\mathrm{H} \mathrm{I})^{1.4 \pm 0.3}$; the Spearman rank correlation coefficient is 0.45 .

(A color version of this figure is available in the online journal.)

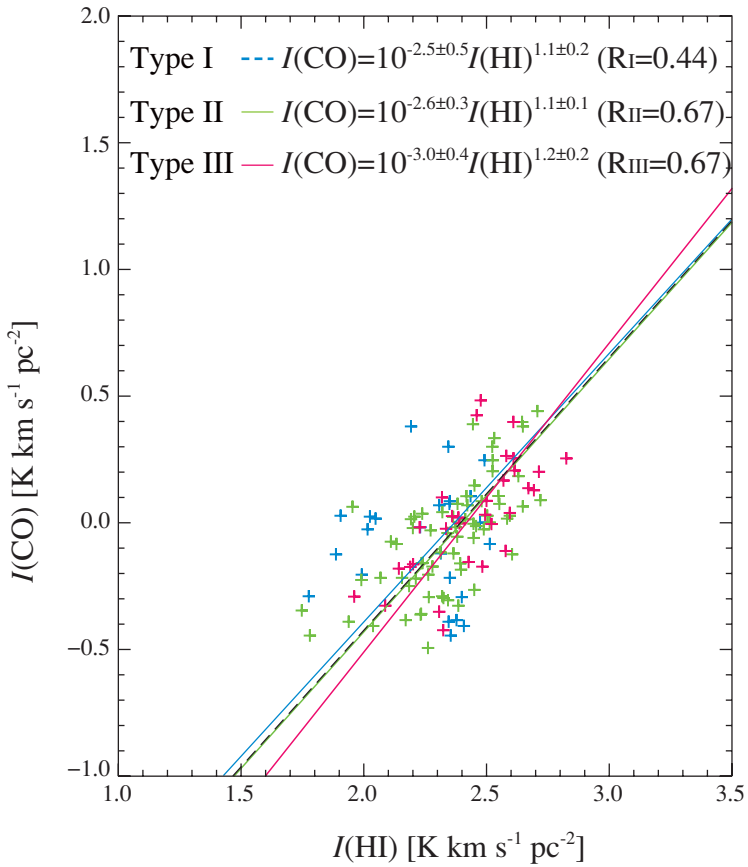

Figure 12. CO vs. $\mathrm{HI}$ integrated intensity for the 123 clouds in our sample, averaged over the projected area of each GMC or $\mathrm{H}$ I envelope. Blue, green, and red plot symbols represent Type I, Type II, and Type III GMCs, respectively. The black dotted line shows the regression line for all the 123 clouds; $I(\mathrm{CO})$ $=10^{-2.6 \pm 0.2} I(\mathrm{HI})^{1.1 \pm 0.1}$. The regression lines and Spearman rank correlation coefficients $\left(R_{\mathrm{I}}, R_{\mathrm{II}}\right.$, and $\left.R_{\mathrm{III}}\right)$ for the three GMC types are shown at the top of the plot.

(A color version of this figure is available in the online journal.)

gravity of a GMC and possibly from a converging flow driven by super bubbles, while the thermal motion is negligibly small $1.4-3 \mathrm{~km} \mathrm{~s}^{-1}$ for kinetic temperatures of $\sim 150-600 \mathrm{~K}$. We can roughly estimate the infall velocity to be half of the $\mathrm{HI}$ line width, i.e., $\sim 7 \mathrm{~km} \mathrm{~s}^{-1}$. This value is consistent with the free-fall velocity, $\sim 6 \mathrm{~km} \mathrm{~s}^{-1}$, for a typical Type II GMC. For spherical accretion, where the GMC is surrounded by an $\mathrm{H}$ I envelope with a radius of $\sim 40 \mathrm{pc}$, volume density of $n(\mathrm{HI}) \sim 10 \mathrm{~cm}^{-3}$, and an infall speed of $\sim 7 \mathrm{~km} \mathrm{~s}^{-1}$, we estimate the mass accretion rate to be $\sim 0.05 M_{\odot} \mathrm{yr}^{-1}$. Over the typical timescale of the GMC evolution, i.e., $\sim 10 \mathrm{Myr}$, the increase in molecular mass amounts

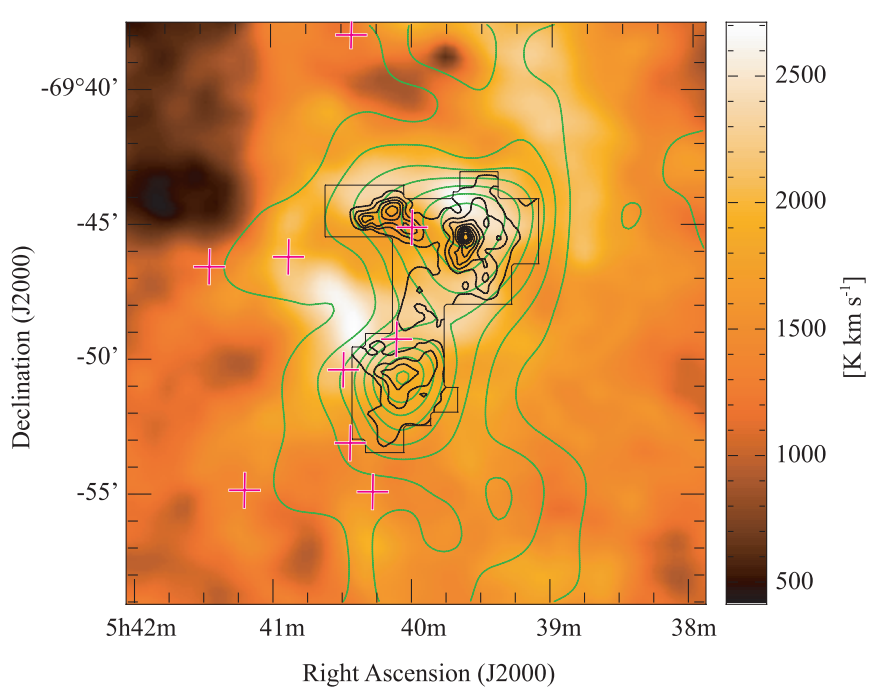

Figure 13. $\mathrm{CO}$ and $\mathrm{HI}$ emission in the N159 region. The gray-scale image represents the combined ATCA+Parkes $\mathrm{H}$ I integrated intensity data (Kim et al. 2003). The black contours are integrated $\mathrm{CO}(J=3-2)$ emission by ASTE (Minamidani et al. 2008) and green contours are integrated CO $(J=1-0)$ emission by NANTEN (Fukui et al. 2008). For CO $(J=3-2)$, the contour levels are from $5 \mathrm{~K} \mathrm{~km} \mathrm{~s}^{-1}$ in $10 \mathrm{~K} \mathrm{~km} \mathrm{~s}^{-1}$ intervals; for $\mathrm{CO}(J=1-0)$, the contours levels are from $1.2 \mathrm{~K} \mathrm{~km} \mathrm{~s}^{-1}$ in steps of $2.4 \mathrm{~K} \mathrm{~km} \mathrm{~s}^{-1}$. The thin black lines indicate the region observed in $\mathrm{CO}(J=3-2)$ emission by ASTE. The crosses indicate the positions of H II regions cataloged by Davies et al. (1976).

(A color version of this figure is available in the online journal.)

to $\sim 5 \times 10^{5} M_{\odot}$, which is roughly consistent with the observed typical value for the mass of a Type III GMC $\left(\sim 4 \times 10^{5} M_{\odot}\right.$, Table 1). In the evolutionary picture, the mass accretion of a GMC is terminated by the violent disruption and/or ionization of the molecular material by stellar winds and ionization from young stars.

The infall scenario offers a reasonable interpretation of the $\mathrm{HI}$ and CO properties of GMCs that we have explored in this paper. It remains to be seen, however, if an infall velocity field is consistent with 2D observations; careful analysis of an isolated $\mathrm{HI}$ envelope with little kinematical disturbance or nearby contamination could be used to verify this. It is also important to clarify whether the $\mathrm{HI}$ line width is affected by turbulence to a significant degree.

It could be argued that the $\mathrm{H}$ I gas surrounding GMCs is supplied by the recombination of $\mathrm{H}$ II into $\mathrm{H} \mathrm{I}$, as both Type II and Type III GMCs are associated with $\mathrm{H}$ II regions. This alternative seems unlikely, however: first, the H II regions in Type II GMCs are compact and therefore do not constitute a significant mass reservoir; second, the H I envelope in Type III GMCs are not spatially well matched with the $\mathrm{H}$ II regions and clusters. In $\mathrm{N} 159$, for instance, the $\mathrm{H}$ II regions and young clusters are confined to the north of the GMC, whereas the $\mathrm{HI}$ is more widely distributed in the east and south (Figure 13).

\section{2. $\mathrm{H}_{\mathrm{I}}-\mathrm{H}_{2}$ Conversion in GMCs}

This study has shown that the $\mathrm{HI}$ and $\mathrm{CO}$ distributions correlate well on 40-100 pc scales. It is worth noting, however, that the correlation becomes less clear on smaller scales of $\sim 10$ pc within a GMC. Figure 13 shows an overlay of the $\mathrm{H}$ i and $\mathrm{CO}$ distributions for the Type III GMC N159, where the CO data were obtained using the ASTE $10 \mathrm{~m}$ submillimeter telescope in the ${ }^{12} \mathrm{CO} J=3-2$ emission line (Minamidani et al. 2008). Figure 13 shows that the $\mathrm{HI}$ becomes less bright at $T_{\mathrm{b}}(\mathrm{HI})$ $70-80 \mathrm{~K}$ toward N159E at (R.A., decl.) $=\left(5^{\mathrm{h}} 40^{\mathrm{m}},-69^{\circ}, 45^{\prime}\right)$, 
compared to intensities of $T_{\mathrm{b}}(\mathrm{H} \mathrm{I}) \sim 120 \mathrm{~K}$ in the $\mathrm{H}$ I envelope. A similar behavior was noted by Ott et al. (2008). This is unlikely to be caused by absorption of the radio continuum emission, as there is no radio continuum emission toward N 159E. We regard this behavior to be illustrative of the conversion of $\mathrm{H} \mathrm{I}$ into $\mathrm{H}_{2}$, as well as the lower spin temperature in the interior of a GMC. In the inner part of a GMC, $\mathrm{HI}$ is converted into $\mathrm{H}_{2}$ via reactions on grain surfaces on a timescale of $\sim 10 \mathrm{Myr}$. The H I density is typically $\sim 1 \mathrm{~cm}^{-3}$, compared to a total molecular density of a few $100 \mathrm{~cm}^{-3}$, corresponding to atomic to molecular hydrogen ratio of $\sim 100$ (e.g., Allen \& Robinson 1977; Spitzer 1978; Goldsmith et al. 2007). The spin temperature is also lower, and is likely to equal the molecular gas kinetic temperature of $\sim 60$ K (e.g., Sato \& Fukui 1978; Mizuno et al. 2009). In the H I envelope, on the other hand, the spin temperature is probably between $\sim 150$ and $600 \mathrm{~K}$ and the $\mathrm{HI}$ density is estimated to be $\sim 10 \mathrm{~cm}^{-3}$ with no $\mathrm{H}_{2}$. The lower $T_{\mathrm{b}}(\mathrm{HI})$ in the interior is likely due to the lower spin temperature and the lower $\mathrm{HI}$ density. The mass of the apparently cold $\mathrm{H}$ I gas toward N159E is approximately $10 \%$ of the mass of the $\mathrm{H}_{\mathrm{I}}$ envelope, $\sim 10^{5} \mathrm{M}_{\odot}$, if we assume that the cold $\mathrm{H}_{\mathrm{I}}$ is optically thin, which suggests that the cold H I within the GMC is not a dominant mass component of the atomic+molecular cloud complex.

It has been shown that there are cold $\mathrm{H}$ I components in the LMC as measured from emission and absorption observations toward radio continuum sources (Dickey et al. 1994). These authors detected $\mathrm{H}_{\mathrm{I}}$ absorption features toward 19 of 30 continuum sources in the LMC and argued that $T_{\mathrm{s}}$ of the cold components can be as low as $40 \mathrm{~K}$. Such cold H I components may be associated with GMCs. It is however not clear observationally how the cold $\mathrm{HI}_{\mathrm{I}}$ in absorption is related to GMCs because none of the absorption measurements by Dickey et al. (1994) coincide with the NANTEN GMCs.

An issue which has been raised in Wong et al. (2009) is that higher $\mathrm{H}_{\mathrm{I}}$ intensity is a necessary but not sufficient condition for $\mathrm{CO}$ formation. In other words, there are many places with high $\mathrm{H}$ i intensities in the LMC without CO. The current analysis has focused solely on the H I gas surrounding GMCs and therefore does not directly address this issue. We note, however, that it is possible that $\mathrm{HI}$ gas with the same intensity can have a significantly different density. We propose an interpretation that the atomic gas in regions with high $\mathrm{H}$ i intensities but no $\mathrm{CO}$ may have lower densities and higher temperatures. This interpretation could be tested in the future by high velocityresolution $\mathrm{H}$ I observations that can resolve subtle variations in H I profiles and hence identify spatial variations of the atomic gas temperature.

\section{SUMMARY}

We have carried out the first 3D analysis of the connection between the $\mathrm{CO}$ and $\mathrm{H}$ i emission in a galaxy. The major results of our study are as follows.

1. A $3 \mathrm{D}$ comparison at a resolution of $40 \mathrm{pc} \times 40 \mathrm{pc} \times$ $1.7 \mathrm{~km} \mathrm{~s}^{-1}$ has revealed that the fraction of $\mathrm{HI}$ associated with $\mathrm{CO}$ tends to increase as a monotonic function of $\mathrm{HI}$ intensity without a sharp threshold for the $\mathrm{CO}$ formation.

2. We find that GMCs are associated with $\mathrm{H}$ I envelopes on scales of $\sim 50-100 \mathrm{pc}$. The $\mathrm{HI}_{\mathrm{I}}$ envelopes have typical volume densities of $\sim 10 \mathrm{~cm}^{-3}$ and an average line width of $\sim 14 \mathrm{~km} \mathrm{~s}^{-1}$, which is about three times larger than the line width of $\mathrm{CO}$. We argue that the $\mathrm{H}$ I envelopes are gravitationally bound by GMCs.
3. For 123 GMCs with single-peaked Hi profiles, we find a correlation such that [average $\mathrm{CO}$ intensity] $\propto$ [average $\mathrm{H} \mathrm{I}$ intensity $]^{1.1 \pm 0.1}$. There is a clear increase of the associated $\mathrm{H}$ I intensity from GMC Type I to Type III.

4. We interpret our results to mean that a GMC increases in mass via continuous $\mathrm{HI}_{\mathrm{I}}$ accretion over a timescale of $\sim 10 \mathrm{Myr}$ and with a mass accretion rate of $0.05 M_{\odot} \mathrm{yr}^{-1}$, before being disrupted by ionization and stellar winds from young clusters. The accreted $\mathrm{H}_{\mathrm{I}}$ is likely to be converted to molecular hydrogen due to the higher shielding within a GMC.

The NANTEN project is based on a mutual agreement between Nagoya University and the Carnegie Institution of Washington (CIW). We greatly appreciate the hospitality of all the staff members of the Las Campanas Observatory of CIW. We are thankful to the many Japanese public donors and companies who contributed to the realization of the project. This study has made use of SIMBAD Astronomical Database and NASA's Astrophysics Data System Bibliographic Services. This work is financially supported in part by a Grant-in-Aid for Scientific Research from the Ministry of Education, Culture, Sports, Science and Technology of Japan (No. 15071203), from JSPS (No. 14102003, No. 18684003, No. 20244014, and core-tocore program 17004). N.M. acknowledges the support of the Sumitomo Foundation, and T.O. of the Mitsubishi Foundation.

\section{REFERENCES}

Allen, M., \& Robinson, G. W. 1977, ApJ, 212, 396

Andersson, B. -G., Wannier, P. G., \& Morris, M. 1991, ApJ, 366, 464

Bica, E., Claria, J. J., Dottori, H., Santos, J. F. C., Jr., \& Piatti, A. E. 1996, ApJS, 102,57

Blitz, L., Fukui, Y., Kawamura, A., Leroy, A., Mizuno, N., \& Rosolowsky, E. 2007, in Protostars and Planet V, ed. B. Reipurth, D. Jewitt, \& K. Keil (Tucson, AZ: Univ. Arizona Press), 951

Davies, R. D., Elliott, K. H., \& Meaburn, J. 1976, MmRAS, 81, 89

Dickey, J. M., Mebold, U., Marx, M., Amy, S., Haynes, R. F., \& Wilson, W. 1994, A\&A, 289, 357

Dobashi, K., Bernard, J. P., Hughes, A., Paradis, D., Reach, W. T., \& Kawamura, A. 2008, A\&A, 484, 205

Fukui, Y. 2007, in IAU Symp. 237, Triggered Star Formation in a Turbulent ISM, ed. B. Elmegreen \& J. Palous (Cambridge: Cambridge Univ. Press), 31 Fukui, Y., et al. 1999, PASJ, 51, 745

Fukui, Y., et al. 2008, ApJS, 178, 56

Goldsmith, P., Li, D., \& Krco, M. 2007, ApJ, 654, 273

Hasegawa, T., Sato, F., \& Fukui, Y. 1983, AJ, 88, 658

Imara, N., \& Blitz, L. 2007, ApJ, 662, 969

Israel, F. P., Maloney, P. R., Geis, N., Herrmann, F., Madden, S. C., Poglitsch, A., \& Stacey, G. J. 1996, ApJ, 465, 738

Kawamura, A., et al. 2009, ApJS, 184, 1

Kennicutt, R. C., Jr. 1998, ApJ, 498, 541

Kim, S., Dopita, M. A., Staveley-Smith, L., \& Bessel, M. S. 1999, AJ, 118, 2797

Kim, S., Staveley-Smith, L., Dopita, M. A., Sault, R. J., Freeman, K. C., Lee, Y., \& Chu, Y.-H. 2003, ApJ, 148, 473

Minamidani, T., et al. 2008, ApJS, 175, 485

Mizuno, N., Muller, E., Maeda, H., Kawamura, A., Minamidani, T., Onishi, T., Mizuno, A., \& Fukui, Y. 2006, ApJ, 643, 107

Mizuno, N., Rubio, M., Mizuno, A., Yamaguchi, R., Onishi, T., \& Fukui, Y. 2001, PASJ, 53, L45

Mizuno, Y., et al. 2009, PASJ, submitted

Ott, J., et al. 2008, PASA, 25, 129

Sato, F., \& Fukui, Y. 1978, AJ, 83, 1607

Schmidt, Th. 1972, A\&A, 16, 95

Spitzer, L., Jr. 1978, Physical Processes in the Interstellar Medium (New York: Wiley Interscience)

Wannier, P. G., Lichten, S. M., \& Morris, M. 1983, ApJ, 268, 727

Wong, T., et al. 2009, ApJ, 696, 370 (Paper I)

Yamaguchi, R., et al. 2001, PASJ, 53, 9 